\title{
ANATOMY AND PHYSIOLOGY OF EXPERIMENTALLY PRODUCED STRIPED TECTA ${ }^{1}$
}

\author{
MARGARET I. LAW ${ }^{2}$ AND MARTHA CONSTANTINE-PATON
}

Department of Biology, Princeton University, Princeton, New Jersey 08544

\begin{abstract}
Transplantation of a third eye primordium to the forebrain region of a frog (Rana pipiens) embryo causes two retinal projections to converge on a single tectal lobe. These projections form stereotyped eye-specific termination bands (Constantine-Paton, M., and M. I. Law (1978) Science 202: 639-641) that are similar to the source-specific stripes found normally in many regions of the mammalian brain. In the present study, we use quantitative analyses of anatomical data and double labeling techniques to demonstrate that induced bands of three-eyed frogs are approximately 200 $\mu \mathrm{m}$ wide, that they invariably run in a rostrolateral to caudomedial direction, and that they represent interdigitating synaptic zones which fill the entire superficial neuropil of the dually innervated tectal lobe. This periodic segregation pattern is not seen in the superinnervated diencephalon or in the optic tracts.

Morphometric measurements on animals with dually innervated tectal lobes revealed an approximate $30 \%$ hyperplasia that was restricted largely to the deeper predominantly cellular tectal layers. Each of the banded retinal projections occupied neuropil volumes that were roughly $50 \%$ smaller than the volume occupied by the noncompeting retina of the same animal.

Eye-specific segregation was detected with extracellular recording techniques as an ability of one of the two eyes to elicit consistently more and larger action potentials throughout a radial penetration of the superficial tectal neuropil. In several preparations, electrolytic lesions confirmed that physiologically defined positions of eye dominance corresponded to a band from the same eye. Maps of the visual field projections within dually innervated tecta were relatively normal and their orientation was consistent with the initial embryonic orientation of the retinas.

Eye laterality, time of arrival, or fasciculation during growth are not responsible for this induced banding. Instead, our results are attributed to two mechanisms that are probably fundamental to neural mapping. These are: differential affinities between retinal and tectal loci which normally align the projection by bringing together appropriate pre- and postsynaptic areas and interactions among retinal ganglion cell fibers. The latter causes axons from physically neighboring retinal ganglion cell bodies to terminate together within the tectum and consequently increases the internal order of the map. We propose that these same two mapping mechanisms may be responsible for the afferent segregation found in diverse regions of many vertebrate brains.
\end{abstract}

Axons from the ganglion cells of the frog eye form retinotopically ordered synapses within the contralateral optic tectum. This primary visual projection is normally continuous throughout the entire superficial neuropil of the tectal lobe. However, it can be disrupted predictably if an extra eye is added to the forebrain region of an early embryo or if one tectum is removed from young postmetamorphic frogs (Constantine-Paton and Law, 1978; Law and Constantine-Paton, 1980). Both of these procedures force fibers from two eyes to share a single optic

\footnotetext{
'This work was supported by National Institutes of Health Grant EY01872. We wish to thank P. Ferrari-Eastman for technical assistance on this project and M. Davis for her helpful advice on the manuscript.

${ }^{2}$ To whom correspondence should be addressed.
}

lobe. 'The invariant result is that terminals from each of the two retinas segregate into alternating, $200-\mu \mathrm{m}$-wide, eye-specific bands (Constantine-Paton and Law, 1978; Law and Constantine-Paton, 1980).

Patterns of afferent segregation quite similar to the experimentally produced bands in Rana pipiens have become increasingly recognized as a basic structural component in diverse regions of the mammalian brain. For example, thalamic afferents to the visual cortex in cats and monkeys originate from eye-specific lateral geniculate layers and maintain this segregation in the cortex, forming ocular dominance columns (Hubel and Wiesel, 1969; Wiesel et al., 1974; LeVay et al., 1975; Shatz et al., 1977; Casagrande and Skeen, 1980). Analogous synaptic zones have been observed among commissural and cor- 
tico-cortical projections to visual (Gilbert and Wiesel, 1980; Newsome and Allman, 1980), somatic sensory (Jones et al., 1975; Shanks et al., 1975; Wise and Jones, 1976), auditory (Imig and Brugge, 1978; Fitzpatrick and Imig, 1980), limbic, motor, and associative cortices (Goldman and Nauta, 1977a; Jones et al., 1978; Künzle, 1976) and within brainstem regions, such as the superior colliculus (Rakic, 1977; Wise and Jones, 1977; Hubel et al., 1975; Graybiel, 1976, 1978; Pollack and Hickey, 1979; Graybiel and Ragsdale, 1980) and cerebellum (Oscarsson, 1973; Courville, 1975; Groenewegen and Voogd, 1977; Groenewegen et al., 1979). Non-banded segregation, vibrissal barrels (Woolsey and Van der Loos, 1970; Killackey, 1973), cortical-caudate annuli (Goldman and Nauta, 1977b), and retinocollicular "puffs" (Graybiel, 1975) also have been reported.

The widespread occurrence of such stereotyped synaptic patterns suggests that important cellular interactions are involved in their formation. Nevertheless, the nature of these interactions remains obscure and relatively difficult to study in the central nervous systems of internally developing mammals.

This report details our analysis of the banded pattern produced in the retinotectal projection of three-eyed frogs. We describe anatomical and electrophysiological evidence demonstrating that axons from each of the two eyes maintain retinotopic order while terminating within these eye-specific stripes. Moreover, we propose that the cellular interactions responsible for banding in doubly innervated tecta also act, within the normal frog, to form the precise retinotectal map.

In presenting this detailed description of experimentally induced bands in frog optic tectum, we hope to establish this accessible and malleable preparation as a valid model for subsequent investigations. The amphibians may offer a unique opportunity to decipher principles of stereotyped afferent segregation that ultimately will be generalizable to the brains of all vertebrates.

\section{Materials and Methods}

Embryology. Microsurgery was used to implant a third eye primordium from a Shumway stage 17 to 19 Rana pipiens embryo into the forebrain region of a sibling embryo of the same stage (Shumway, 1940). At this age, the eye is a flattened evagination from the telencephalic vesicle. Few ganglion cells are postmitotic at this stage, but the retinal axes have been determined already (Sharma and Hollyfield, 1974). Experimental tadpoles were maintained in a 1:1 solution of charcoal-treated waler and 15\% Steinberg's solution (Rugh, 1962). They were fed boiled romaine lettuce and Purina trout chow and the solution in which they were kept was changed twice weekly. Postmetamorphic frogs were fed liberally with small crickets (Fluckers Cricket Farm, Baton Rouge, LA) 1 week after tail reabsorption.

Thirty three-eyed tadpoles ranging in age from Taylor and Kollros stage (T \& K St) IV to XXIV (Taylor and Kollros, 1946) and 20 frogs between 1 week and 7 months past metamorphosis were examined for this paper. A preliminary report on 10 of these animals has appeared previously (Constantine-Paton and Law, 1978).

Autoradiography. One to 5 days prior to killing the animal, 10 to $15 \mu \mathrm{Ci}$ of $\left[{ }^{3} \mathrm{H}\right]$ proline $(60$ to 115 or $26 \mathrm{Ci}$ / mmol, New England Nuclear) were injected into the vitreous body of either a supernumerary ( 47 animals) or a normal eye ( 3 animals). Thirty-six of these animals were fixed in Carnoy's fluid or $10 \%$ buffered formalin. Subsequently, their entire skull with exposed brain was embedded in paraffin and sectioned in either the transverse, horizontal, or sagittal plane. Serial $10-\mu \mathrm{m}$ sections were processed for light microscope autoradiography (see Constantine-Paton and Capranica, 1976).

Double label. Eight of the animals with $\left[{ }^{3} \mathrm{H}\right]$ proline injections into their supernumerary eye had their normal superinnervating optic tract labeled either with $10 \mu \mathrm{Ci}$ of $\left[{ }^{14} \mathrm{C}\right]$ proline $(100 \mathrm{mCi} / \mathrm{mmol}$, New England Nuclear) or with the anterograde transport of horseradish peroxidase (HRP, Boehringer). Two tadpoles (T \& K St XXI and T \& K St XIV) were double labeled with $\left[{ }^{3} \mathrm{H}\right]$ proline/ $\left[{ }^{14} \mathrm{C}\right]$ proline and allowed to survive 2 days before fixation, embedding, and sectioning in paraffin as described above. Cleared, serial sections were placed against Kodak x-ray film for 5 to 7 days. This film is only sensitive to the emissions from the ${ }^{14} \mathrm{C}$ isotope. The same sections subsequently were coated with NTB liquid emulsion to localize the ${ }^{3} \mathrm{H}$ isotope. The 3 tadpoles ( $\mathrm{T} \& \mathrm{~K}$ St VIII, $\mathrm{X}$, and XIII) and 3 frogs for which HRP was used as the second label had an HRP-soaked pledget applied to the cut stump of their competing, normal optic nerve 1 day after $\left[{ }^{3} \mathrm{H}\right]$ proline was injected into their supernumerary eye (Scalia and Colman, 1974). The brains of these animals were fixed by vascular perfusion with $3 \%$ glutaraldehyde, $1 \%$ paraformaldehyde in $0.1 \mathrm{M}$ phosphate buffer (pH 7.4). They then were processed according to methods outlined by Law and Constantine-Paton (1980). Alternate, $30-\mu \mathrm{m}$ sections were reacted for HRP localization using a $\mathrm{CoCl}_{2}$-intensified diaminobenzidine procedure (Adams, 1977). The intervening sections were coated for light microscope autoradiography.

Quantification. All measurements were performed from camera lucida tracings of serial transverse sections using a MOP III (Zeiss) image analyzer. Estimates of volumes for both superficial tectal neuropils (layers 7 through 9; Székely and Lázár, 1976) and for entire tectal lobes (layers 1 through 9) were obtained in 5 animals which had demonstrated tectal stripes anatomically. These volumes were calculated from total area measurements multiplied by the thickness of each section (10 or $30 \mu \mathrm{m})$.

Bandwidth histograms were constructed for 7 animals using length measurements of each band and interband at the tectal surface (Fig. 1A). This data, from every other, serial $10-\mu \mathrm{m}$ section, was translated into a straight line representing the partitioned tectal surface. All lines then were positioned at intervals scaled to $20 \mu \mathrm{m}$ so that their midpoints (representing the middle of the tectal neuropil) were in register (Fig. $1 B$ ). This method provided a two-dimensional projection of the banded tectal surface that was oriented consistently and therefore could be compared across different preparations.

Electrophysiology. The physiological effects of double innervation were examined by recording extracellular activity predominantly from retinal ganglion cell terminals (Maturana et al., 1960) in the superficial tectal 

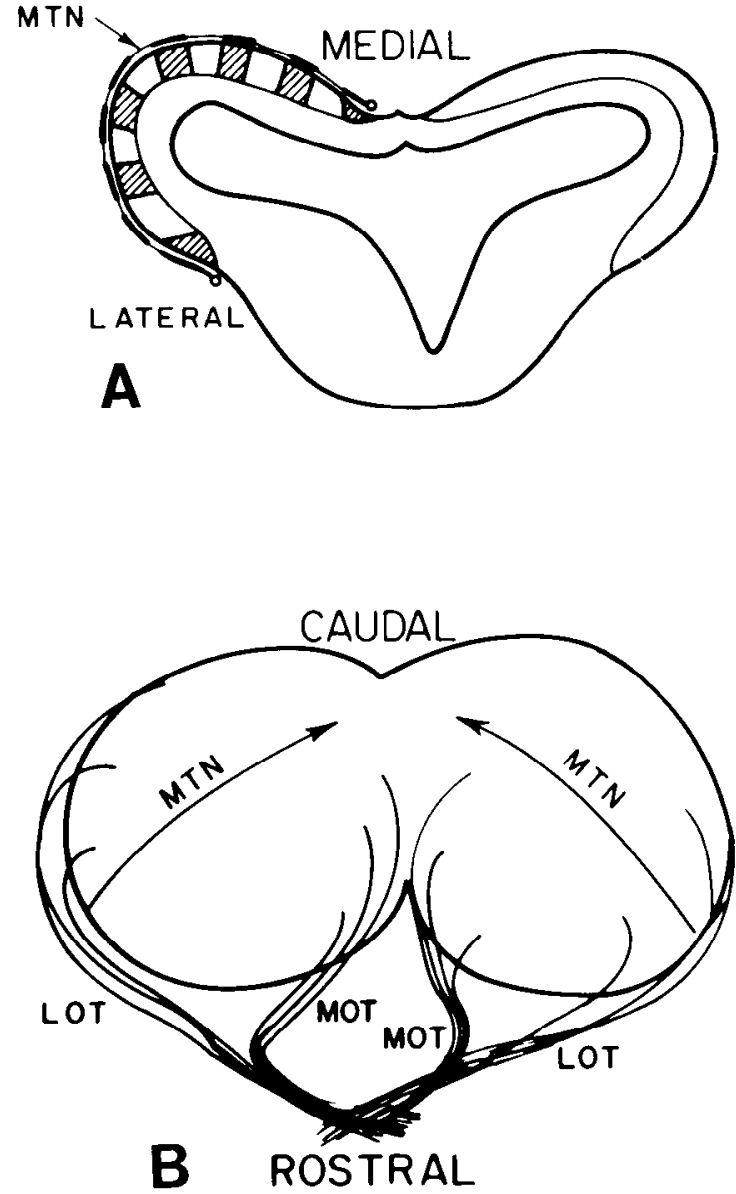

Figure 1. Method of representing the tectum in two dimensions. $A$, Drawing of a transverse section through the optic tectum with the neuropil of the left lobe banded. In order to flatten the surface of these doubly innervated optic lobes, camera lucida tracings were made of every other $10-\mu \mathrm{m}$ serial section. A MOP III image analyzer (Zeiss) then was used to measure the lengths of labeled and unlabeled neuropil from the medial to lateral edges. The sum of all lengths for each section divided by 2 gave the midtectal neuropil $(M T N)$ point. This midtectal point served as a fixed landmark around which the curved line representing each section's neuropil was straightened and aligned. $B$, Pictorial representation of the dorsal tectal surface with each landmark drawn. $M O T$, Medial optic tract; $L O T$, lateral optic tract.

neuropil of 12 three-eyed frogs. Electrodes were glasscoated tungsten plated with gold and platinum to an impedance of approximately 5 megohms.

Prior to recording, both tectal lobes were exposed surgically under MS222 anesthesia $10.5 \%$ tricaine methanesulfonate, $\mathrm{pH} 7.4$, Sigma) and their pial pigment patterns were photographed. Electrode penetrations were made at sites spaced $160 \mu \mathrm{m}$ apart using the photographed pial patterns for reference.

A Bausch and Lomb projection perimeter provided the $3^{\circ}$ light spot used for visual stimulation and simultaneously marked the edges of visual receptive fields on a polar representation of the perimeter's hemisphere. At most recording sites, it was not possible to isolate a single visual unit. Consequently, most of our visual receptive fields represent the area subserved by approximately two to four different units.
Animals were immobilized before and during the mapping sessions by intramuscular or lymphatic injections with $10 \mu \mathrm{l}(1 \mathrm{mg} / \mathrm{ml})$ of tubocurarine chloride (Sigma). They were wrapped in moist gauze that was pinned securely on an elevated stage centered within the perimeter's arch. An effort was made to position each frog individually so that the maximal extent of both the double innervating normal and supernumerary eye visual fields fell within the perimeter's hemisphere. In most cases, this involved tilting the perimeter $15^{\circ}$ up from the horizontal and "centering" the animal relative to a plane midway between the normal and transplanted eye. Once positioned, the frog was not moved throughout the approximately $6-\mathrm{hr}$ recording session. Ambient temperature in the recording room was maintained between 16 and $18^{\circ} \mathrm{C}$ in order to increase the viability of the preparation and to minimize the number of curare injections necessary to keep the animal immobile.

Black corneal occluders were used to assure stimulation of only one eye at a time. Responses to turning off or on the $3^{\circ}$ light spot in a darkened room were used to define the edges of the visual field at every tectal site.

Generally, for each penetration in the doubly innervated tectum, the electrode detected visual activity from both the supernumerary and the normal eye. Consequently, for a physiological demonstration of eye-specific segregation within the tectal neuropil, an eye dominance test was performed. In most tests, a fiber optics light pipe connected to a pen flashlight was shone into the entire pupil of first one eye and then the other. The strength of the response from each eye was judged and eye dominance was assigned for each electrode position based on the relative size and number of action potentials driven by each retina. Occasionally, eye dominance was determined during mapping. In these cases, the relative strength of one eye's response to turning off and on the $3^{\circ}$ perimeter light at the center of its receptive field was compared to the other eye's response at the center of its field. Most "eye dominance" tests were taped for later analysis on a TEAC model A-2340 tape recorder.

\section{Results}

Transplanted optic nerve trajestory and innervation patterns. The central trajectory of the supernumerary optic projection was followed through serial sections in 30 three-eyed animals. In most cases (18 animals), the supernumerary optic nerve penetrated the brain at the level of the diencephalon but rostral to the normal optic chiasm. In one case, penetration occurred directly into the host's telencephalon, while in 9 other animals, axons from the supernumerary retina entered ectopic tissue fused to the generally distorted telencephalic lobe of the host. In most of these preparations, ventricular development and nuclear groups indicated that the ectopic tissue was of donor diencephalic origin (Constantine-Paton and Capranica, 1976; Constantine-Paton, 1978). Nevertheless, the transplanted visual axons invariably left this tissue and traversed the host's telencephalon and diencephalon to form an extensive termination field in the mesencephalic tectal lobes. Finally, in 2 animals, the supernumerary optic nerve was found to be fused to the normal optic nerve and entered the chiasm directly. 

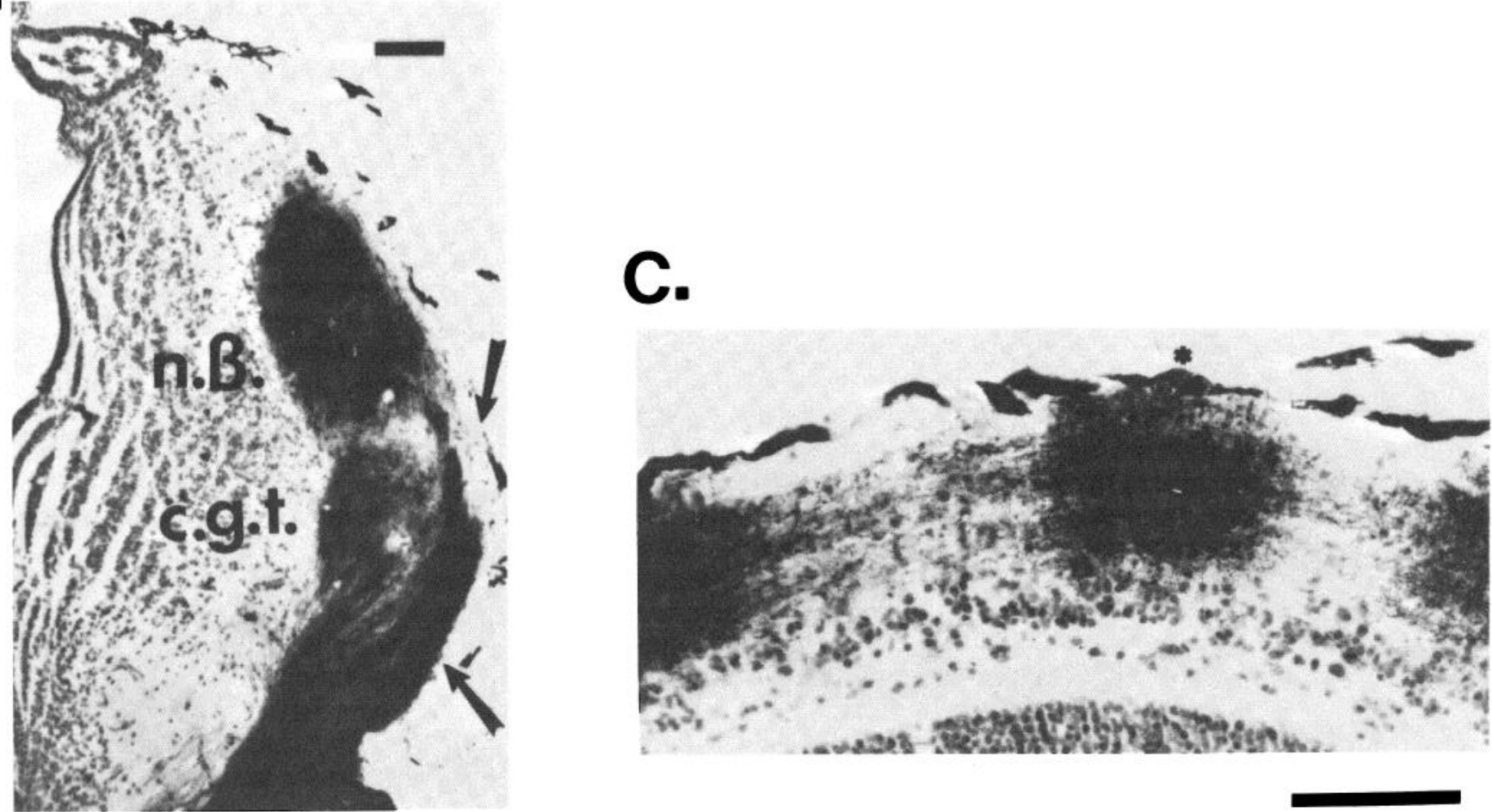

B.
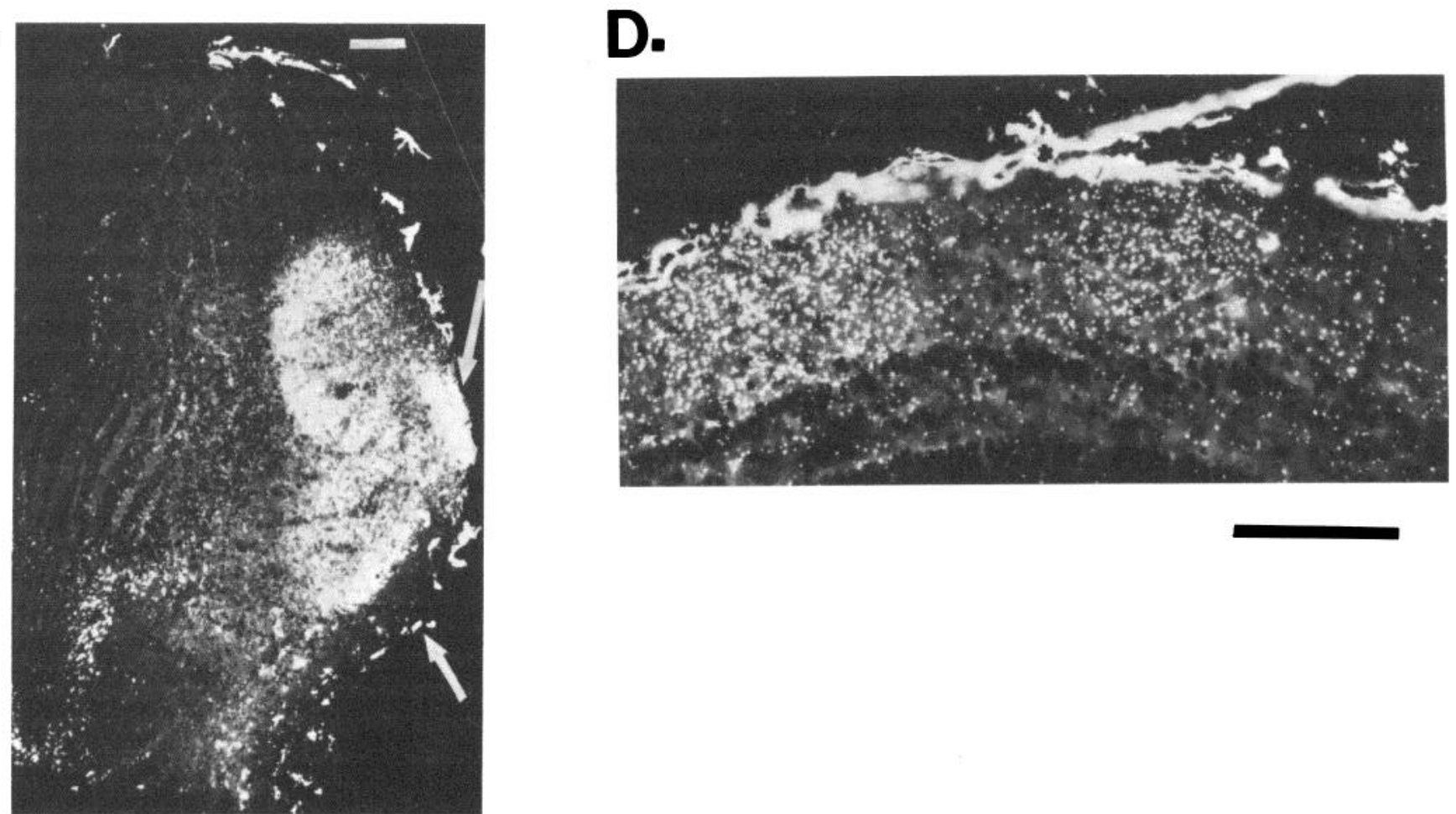

Figure 2. Double labeling of the supernumerary and normal optic projections. $A$ and $B$ are adjacent, 30- $\mu$ m sections through the diencephalon of a 1-week postmetamorphic frog whose supernumerary eye had been injected with $\left[{ }^{3} \mathrm{H}\right]$ proline and whose normal optic nerves had been filled with horseradish peroxidase (HRP). $A$, Light-field photomicrograph of the normal eye optic tract and innervation pattern in the neuropil of Bellonci (n.B.) and the corpus geniculatum thalamicum (c.g.t.). B, Autoradiographic grains in dark-field photomicrograph of the adjacent diencephalic section showing the supernumerary eye's projection to the same neuropil regions. Arrows indicate complementary areas. The top arrows mark a portion of the optic tract from the supernumerary eye. The bottom arrows point out an area where only normal eye fibers are located. A stereotyped pattern of segregation is not seen in the optic tracts or diencephalic nuclei of this animal. $C$ and $D$, Periodic banded pattern observed within the same animal's optic tectum. Adjacent, $30-\mu \mathrm{m}$ sections are pictured again with the right normal eye's projection shown in $C$ and the supernumerary eye's termination field in $D$. Asterisks mark the site of insertion of a piece of pial pigment in both sections which demonstrates the interdigitating nature of the eye-specific bands. Label in the interband region of $C$ is localized predominantly within axon cylinders that run between the termination bands. All scale bars $=100 \mu \mathrm{m}$. 
The laterality of supernumerary visual projections appeared to be determined by the position of the retinal fibers when they penetrated the brain. In general, ventrally entering nerves sent most of their axons to the opposite side of the brain, while more dorsally and laterally penetrating fibers grew to the ipsilateral optic tectum. In all cases, the supernumerary optic tract was found adjacent to the glial limiting membrane (Constantine-Paton, 1978; Gaze and Grant, 1978). The 5 animals with double label showed the position of these ectopic tracts to be nearly identical to those of the tracts from normal eyes within the diencephalon. Only occasional evidence of eye-specific fasciculation was observed (see arrows in Fig. 2, $A$ and $B$ ).

In all animals examined for this study, some evidence of label from the supernumerary eye was found in the thalamic retinal terminal fields (neuropil of Bellonci, corpus geniculatum thalamicum, arcuate nucleus, and the posterior thalamic neuropil; Scalia et al., 1968; Lázár, 1980). Animals with double labeling revealed that the neuropil of Bellonci and the corpus geniculatum thalamicum received input from both the normal and supernumerary retina (Fig. $2, A$ and $B$ ). Within normal frogs, these neuropil regions show some non-banded segregation between terminals from the contralateral and ipsilateral retinas (Lázár, 1980). However, as can be seen in Figure 2, $A$ and $B$, the segregation between normal and supernumerary projections was not complete in threeeyed animals and regions where one retinal input predominated were irregular in position and in shape. Irrespective of whether the diencephalon was viewed in the horizontal, sagittal, or transverse plane, no evidence of eye-specific striping was obtained.

The situation was markedly different within the midbrain of all three-eyed frogs. At the diencephalic-mesencephalic border, both normal and donor fibers merged into the medial and lateral optic tracts. They then entered the tectal plate to form exclusive, interdigitating zones of eye-specific terminals. Banding occurred regardless of the initial laterality or final position of the supernumerary eye and regardless of its axon's growth pathway. In Figure 2, panels $C$ and $D$ are photomicrographs of consecutive frozen sections from a frog whose supernumerary eye was injected with $\left[{ }^{3} \mathrm{H}\right]$ proline and whose normal optic nerve was labeled with HRP. These transverse sections clearly illustrate the complementary nature of the two projections within the tectal neuropil. Examination of all HRP- and $\left[{ }^{3} \mathrm{H}\right]$ proline-labeled tecta revealed that, whenever the terminals from one eye were banded, the terminals from the other eye also were banded in the alternate section. Moreover, when pial pigment, a piece of membrane, or nicks in the tissue marked corresponding areas of adjacent sections, HRPlabeled neuropil regions in one section filled unlabeled bands in its autoradiographically processed neighbor.

The 2 animals processed for $\left[{ }^{14} \mathrm{C}\right]$ - and $\left[{ }^{3} \mathrm{H}\right]$ proline autoradiography produced results that were also consistent with interdigitation of the normal and supernumerary projections. In these preparations, bands were obvious on the $x$-ray film shadow of the doubly innervated tectal lobe. The densely exposed regions represented higher energy emissions produced by $\left[{ }^{14} \mathrm{C}\right]$ proline in terminals of the host's superinnervating eye. By contrast, when these sections were coated subsequently with NTB emulsion, the regions of neuropil that had produced bands on x-ray film appeared to be labeled continuously. The close apposition of emulsion and tissue with liquid emulsion autoradiography allows detection of the lower energy emissions from the ${ }^{3} \mathrm{H}$-labeled supernumerary eye in addition to the ${ }^{14} \mathrm{C}$-labeled terminals. Thus, both sets of stripes were detected simultaneously and they completely filled the superinnervated neuropil.

HRP histochemistry allowed distinctions to be made between axons and the granular reaction product characteristic of optic nerve terminals (Scalia and Colman, 1974; Colman et al., 1976). Figure $3 A$ shows a tangential section through the posterior tectum of a postmetamorphic three-eyed frog in which the normal optic nerve was labeled with HRP. Under higher magnification (Fig. $3 B$ ), black, filled axons within the interband region can be distinguished from the granular synaptic zones within bands. Analysis of such HRP-filled projections revealed that the granular label was confined largely to band regions. Labeled retinal ganglion cell axons ran in the same general direction as the stripes but could be found to intersect these terminal bands at a wide range of angles that varied across the tectal surface.

Stereotypy in the banding pattern. The regularity of eye-specific zones is obvious in the photographic reconstruction shown in Figure 4. The figure was made by aligning bands in selected photomicrographs through an entire horizontally sectioned right tectum. This animal was 2 weeks past metamorphosis and had had its third eye labeled with $\left[{ }^{3} \mathrm{H}\right]$ proline. The reconstruction illustrates consistency in the width of each termination band and the tendency for bands to run as stripes with relatively few fusions and forks. However, it is impossible, with this procedure, to obtain a clear idea of the orientation of the striped pattern because the curved tectal neuropil must be split in order to represent it in two dimensions.

Therefore, a second tectal flattening technique was developed to reconstruct the banding pattern within these doubly innervated lobes. It was applied to the stripcd tecta of 7 animals of which three typical examples are shown in Figures 5 and 6 . This procedure represents the tectal surface as a measured line from transverse sections (see "Materials and Methods"). Although, it neglects tectal curvature and distorts the dimensions of band and interband, it has the advantage of assuring consistent orientation relative to defined tectal landmarks. Consequently, relatively detailed comparison of the banding pattern can be made across different tecta and hetween different animals.

In Figure 5, panels $A$ and $B$ compare normal eye termination bands (Fig. $5 A$ ) to supernumerary eye termination bands (Fig. $5 B$ ) in 2 postmetamorphic frogs. The tectal surfaces of these animals show quite similar patterns of rostrocaudally extending stripes.

In the majority of three-eyed frogs, the supernumerary optic tracts split in the diencephalon to send some axons to both tectal lobes. In most cases, this split was decidedly asymmetrical so that one tectum appeared completely banded despite the occurrence of one or two supernu- 


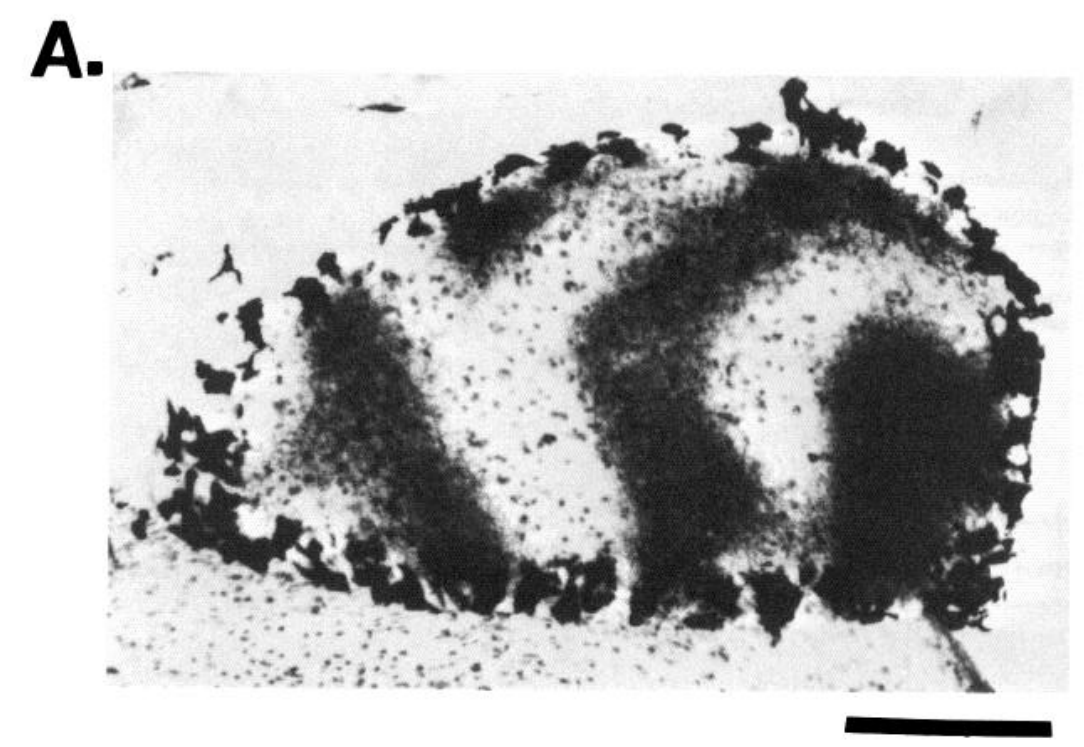

\section{B.}

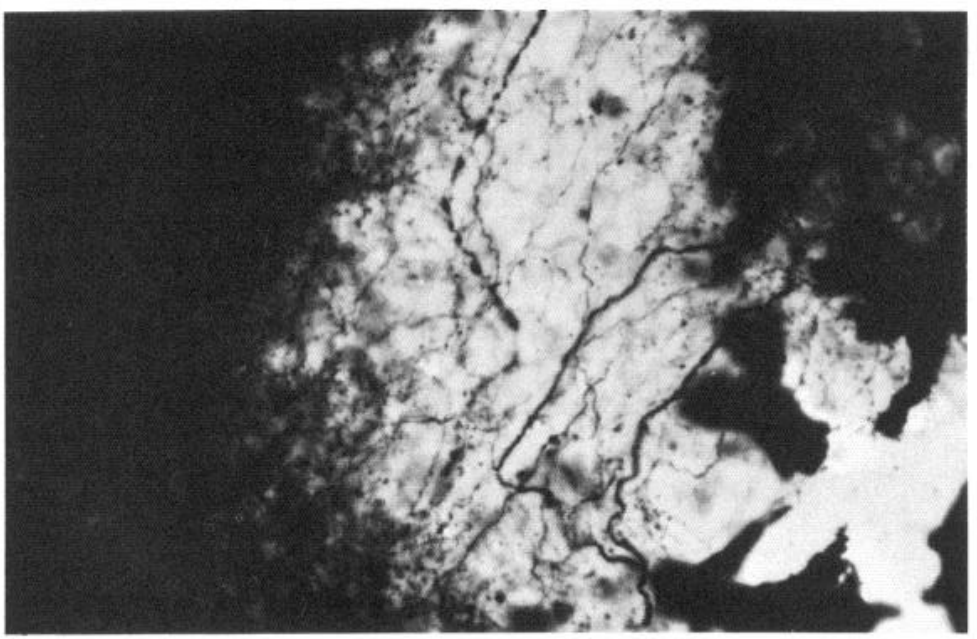

Figure 3. Tangential sections of the banding pattern labeled with the anterograde transport of HRP. A, A low power photomicrograph of a transverse, $30-\mu \mathrm{m}$ section through the posterior tip of the tectal neuropil in a postmetamorphic animal whose doubly innervating right optic nerve had been filled with HRP. Scale bar $=200 \mu \mathrm{m}$. B, A high magnification photomicrograph through the same animal's neuropil. The granular HRP label characteristic of optic terminal areas is confined largely to the bands. Completely filled axons are present in interband regions. The axons can intersect banded areas at a variety of angles. Scale bar $=100 \mu \mathrm{m}$.

merary eye bands in the opposite optic lobe. ${ }^{3}$ In the 10 preparations where significant numbers of supernumerary axons innervated both optic tecta, serial section analysis revealed a complementary pattern of innervation. Generally, a small "hole" in the banding pattern of

\footnotetext{
${ }^{3}$ This ability of one projection to completely band in one tectum and yet produce additional bands in the second lobe probably reflects a phenomenon noted previously in single tectum frogs (Law and Constantine-Paton, 1980). Above a certain critical density of optic fibers, a superinnervating projection will form bands even though the density of innervation within a band can vary dramatically (Law and ConstantinePaton, 1980).
}

one lobe appeared to be matched within several sections by a few symmetrically placed bands in the opposite lobe. The flattened right and left tectal lobes from a T \& K St XII tadpole appear in Figure 6 and demonstrate this effect. In this animal, the supernumerary optic fibers entered near the normal chiasm and divided so that roughly half of the axons innervated the ipsilateral (left) lobe, while the remainder innervated the contralateral (right) optic tectum. The patterns in each lobe are highly complementary. Central tectum which is not banded in the left lobe is banded on the right. The reciprocal nature of these split banding patterns would be expected if fibers from transplanted eyes terminate selectively in tectal 


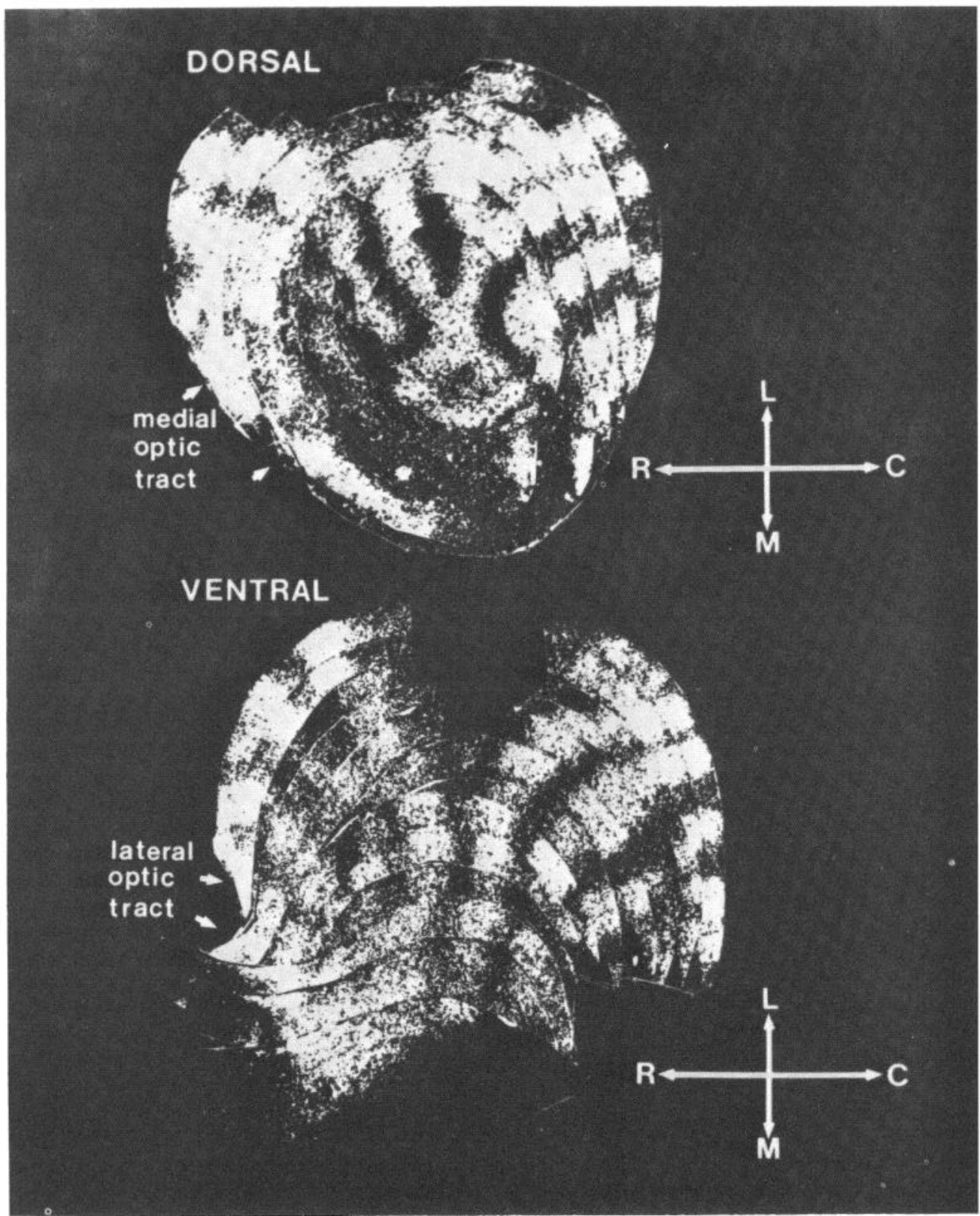

Figure 4. Photographic reconstruction of the stripes in the right tectal lobe of a postmetamorphic frog whose supernumerary eye had been injected with $\left[{ }^{3} \mathrm{H}\right]$ proline. Dark-field photomicrographs were taken of selected $10-\mu \mathrm{m}$, horizontal sections through this tectum. The dorsal surface of the tectal lobe appears in the top reconstruction with the medial optic tract indicated. The axes $(R$, rostral; $C$, caudal; $L$, lateral; $M$, medial) refer to the orientation of the central, most dorsal section. Subsequent sections are aligned according to the banding pattern only and are rotated relative to their actual orientation in the animal. The ventral surface is similarly reconstructed below with the lateral optic tract marked. The axes refer to the most ventral section. In order to flatten the curved tectal surface, it was necessary to split some of the photomicrographs.

areas determined by the region of the retina from which they arise.

Volumetric effects of superinnervation. It was generally possible to assess the degree of double innervation of the tecta upon surgical exposure of the midbrain in threeeyed animals. Tecta, subsequently proven to be striped, appeared larger than their contralateral counterpart upon visual inspection. Quantitative measurements con- firmed this impression. In 4 out of the 5 animals shown in Tables I and II, one tectal lobe was banded completely and the other lobe showed little or no evidence of supernumerary innervation. Comparisons within these 4 animals are shown in the top part of Table I. Volume increases were apparent in both entire tectal lobe and superficial neuropil measurements. This increase, however, was not due primarily to the presence of more 



Figure 5. Comparison of stripes from a normal and a supernumerary eye. Surface reconstructions of doubly innervated tectal lobes from 2 three-eyed frogs using the methods outlined in Figure 1. A, Banding pattern observed in the left tectal lobe of a 2-to 3-month postmetamorphic frog (No. 122) whose normal, right eye had been injected with $\left[{ }^{3} \mathrm{H}\right]$ proline. $B$, Banding pattern within the left tectal lobe of a 4-month postmetamorphic frog (No. 357) whose third eye had been labeled autoradiographically. In both animals, the pattern of stripes extends in a rostrocaudal direction with few forks or fusions. $M T N$, Middle of the tectal neuropil.

retinal fibers within the superficial neuropil since total neuropil enlargements never exceeded $11 \%$, while overall tectal increases averaged $27 \%$. Thus, hyperplasia of the deeper cell and fiber laminae must be occurring in these doubly innervated optic lobes.

The upper part of Table II contains comparisons of the amount of neuropil innervated by the normal versus the supernumerary eye for the same 4 animals. The table reveals that both eyes obtained approximately the same amount of synaptic space. Volumes of banded neuropil equaled volumes of interband neuropil regardless of whether the transplanted or normal eye was labeled and regardless of the age of the animal (see tadpoles 125 and 142). Table II also shows that the total volume of neuropil innervated by any of the competing retinas was always considerably less than the volume of neuropil in which the noncompeting retina terminated. The percentage of reduction in the doubly innervated lobes are summarized in the last column of Table II. Each competing retina suffers an approximate $50 \%$ reduction in its tectal neuropil volume.

The third eye of animal 398 grew to both the right and left tectal lobes in a complementary fashion (see Fig. 6). Entire tectal lobe and neuropil measurement (Table I) revealed that both lobes were approximately equal in size. The total labeled neuropil (see Table II) in this split projection is approximately $0.07 \mathrm{~mm}^{3}\left(0.03 \mathrm{~mm}^{3}\right.$ in the left lobe plus $0.04 \mathrm{~mm}^{3}$ in the right lobe). This is equal to the total unlabeled neuropil occupied by each of the host's "normal" eyes $\left(0.07 \mathrm{~mm}^{3}\right.$ in the left lobe and 0.06 $\mathrm{mm}^{3}$ in the right). Thus, for all animals studied quantitatively, competing eyes appear to be balanced closely in ability to obtain tectal synaptic space.

Constancy of bandwidth. The MOP III was used to 


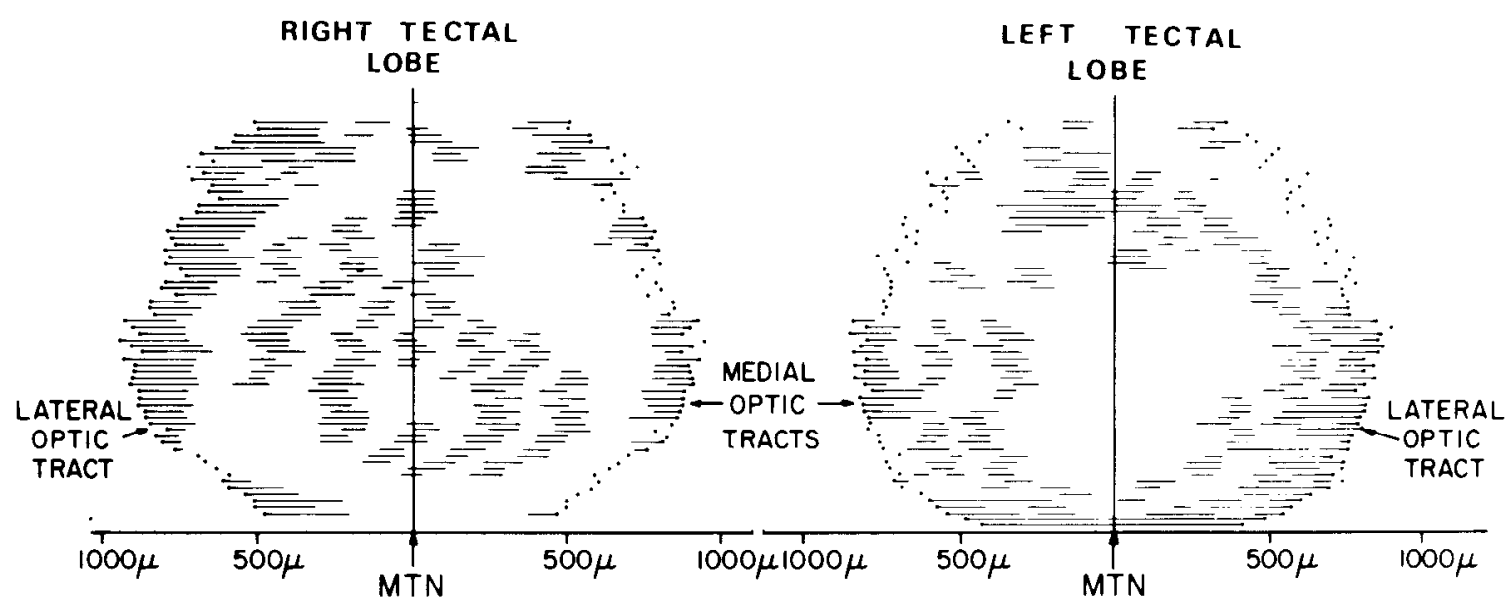

Figure 6. Banding patterns in a bilateral supernumerary eye projection. Flattened representations of both tectal lobes in a T \& K St XII tadpole (No. 398) whose supernumerary eye was labeled with $\left[{ }^{3} \mathrm{H}\right]$ proline. In this animal, the supernumerary optic nerve split at the chiasm to send a large number of axons to both sides of the brain. Both tectal lobes are innervated in a mirror symmetrical, complementary fashion, indicating that fibers from the third eye limit their terminations to specific tectal areas. MTN, Middle of the tectal neuropil.

TABLE I

Tectal volume increases with hyperinnervation

Volumes of superficial neuropil (layers 7 to 9) and entire tectum (layers 1 to 9) were determined. The volumes obtained for the doubly innervated lobe are compared to those of the normal lobe in the same animal.

\begin{tabular}{|c|c|c|c|c|c|c|}
\hline Animal & $\Lambda g c$ & & & $\begin{array}{l}\text { Volume of Doubly In- } \\
\text { nervated Lobe }\end{array}$ & $\begin{array}{l}\text { Volume of Normal } \\
\text { Lobe }\end{array}$ & \% Hyperplasia ${ }^{a}$ \\
\hline \multicolumn{7}{|c|}{$m m^{3}$} \\
\hline \multirow[b]{2}{*}{122} & \multirow{2}{*}{$21 / 2$ months } & \multicolumn{2}{|l|}{$\begin{array}{l}\text { Superficial } \\
\text { neuropil }\end{array}$} & 0.41 & 0.37 & 11 \\
\hline & & \multicolumn{2}{|l|}{$\begin{array}{l}\text { Entire } \\
\text { tectum }\end{array}$} & 1.09 & 0.73 & 49 \\
\hline \multirow[b]{2}{*}{357} & \multirow{2}{*}{4 months } & \multicolumn{2}{|l|}{$\begin{array}{r}\text { Superficial } \\
\text { neuropil }\end{array}$} & 0.41 & 0.37 & 11 \\
\hline & & \multicolumn{2}{|l|}{$\begin{array}{l}\text { neuropil } \\
\text { Entire } \\
\text { tectum }\end{array}$} & 1.08 & 0.85 & 27 \\
\hline \multirow[b]{2}{*}{125} & \multirow[b]{2}{*}{$\mathrm{T} \& \mathrm{~K}$ St IX } & \multicolumn{2}{|l|}{$\begin{array}{r}\text { Superficial } \\
\text { neuropil }\end{array}$} & 0.14 & $0.13^{b}$ & 8 \\
\hline & & $\begin{array}{l}\text { Entire } \\
\text { tectum }\end{array}$ & & 0.46 & $0.38^{b}$ & 21 \\
\hline \multirow[b]{2}{*}{142} & \multirow[b]{2}{*}{ T \& K St XIII } & $\begin{array}{r}\text { Superficial } \\
\text { neuropil }\end{array}$ & & 0.09 & $0.09^{b}$ & $0^{b}$ \\
\hline & & $\begin{array}{l}\text { Entire } \\
\text { tectum }\end{array}$ & & 0.38 & $0.35^{h}$ & $9^{h}$ \\
\hline \multicolumn{7}{|c|}{ Animal with bilateral supernumerary innervation } \\
\hline & \multirow{4}{*}{ T \& K St XII } & \multirow[t]{2}{*}{$\begin{array}{c}\text { Superficial } \\
\text { neuropil }\end{array}$} & $\begin{array}{l}\text { Left } \\
\text { lobe }\end{array}$ & 0.10 & n.a. ${ }^{c}$ & \multirow{2}{*}{ n.a. } \\
\hline \multirow{3}{*}{398} & & & $\begin{array}{l}\text { Right } \\
\text { lobe }\end{array}$ & 0.10 & n.a. & \\
\hline & & \multirow[t]{2}{*}{$\begin{array}{l}\text { Entire } \\
\text { tectum }\end{array}$} & $\begin{array}{l}\text { Left } \\
\text { lobe }\end{array}$ & 0.42 & n.a. & \multirow{2}{*}{ n.a. } \\
\hline & & & $\begin{array}{l}\text { Right } \\
\text { lobe }\end{array}$ & 0.48 & n.a. & \\
\hline
\end{tabular}

\footnotetext{
" \% hyperplasia $=$ volume of banded tectum - volume of normal tectum/volume of normal tectum. Entire tectal lobe volume increases were consistently larger (average percentage of hyperplasia, $27 \%$ ) than superficial neuropil (average, $7.5 \%$ ).

${ }^{h}$ These lobes received a small supernumerary eye projection appearing in only a few sections which represented only a fraction of this predominantly normal tectum.

"n.a., not applicable.
}

confirm our qualitative observations that bandwidth and periodicity are relatively constant. In Figure 7, panels $A$ through $D$ represent histograms of band- and interbandwidth measurements taken from every section of 5 ani- mals. The skewed nature of these distributions arises because the long axes of the bands were not always perpendicular to the plane of sectioning and because sections taken through the points of band fusion also 
TABLE II

Tectal neuropil volumes of competing and normal retinal projections

Both the supernumerary and normal projections sequestered equal neuropil volumes (banded neuropil volumes versus interband neuropil volumes) irrespective of the eye labeled (animal 122 versus animal 357) and regardless of age (animals 125, 398, and 142). The volume of neuropil innervated by either competing retina was approximately half that obtained by a normal, noncompeting eye of the same animal.

\begin{tabular}{|c|c|c|c|c|c|c|c|}
\hline Animal & Age & \multicolumn{2}{|c|}{ Eye Labeled } & $\begin{array}{l}\text { Banded Neuro- } \\
\text { pil Volumes }\end{array}$ & $\begin{array}{l}\text { Interband } \\
\text { Neuropil } \\
\text { Volumes }\end{array}$ & $\begin{array}{l}\text { Normal, Noncom- } \\
\text { peting Eye Neuro- } \\
\text { pil Volumes }\end{array}$ & $\begin{array}{l}\% \text { Reduction }^{a} \\
\text { due to Competi- } \\
\text { tion }\end{array}$ \\
\hline & & & & & $\mathrm{mm}^{3}$ & & \\
\hline 122 & $2^{1 / 2}$ months & \multicolumn{2}{|l|}{ Normal } & 0.2 & 0.21 & 0.37 & 46 \\
\hline 357 & 4 months & \multicolumn{2}{|l|}{ Third } & 0.18 & 0.21 & 0.37 & 51 \\
\hline 125 & T \& K St IX & \multicolumn{2}{|l|}{ Third } & 0.07 & 0.07 & $0.17^{b}$ & 59 \\
\hline 142 & T \& K St XIII & \multicolumn{2}{|l|}{ Third } & 0.04 & 0.05 & 0.09 & 56 \\
\hline \multicolumn{8}{|c|}{ Animal with bilateral supernumerary innervation } \\
\hline \multirow[t]{2}{*}{398} & T \& K St XII & Third & $\begin{array}{l}\text { Left } \\
\text { lobe }\end{array}$ & 0.03 & 0.07 & & \\
\hline & & & $\begin{array}{l}\text { Right } \\
\text { lobe }\end{array}$ & 0.04 & 0.06 & n.a. ${ }^{c}$ & n.a. \\
\hline
\end{tabular}

\footnotetext{
${ }^{a} \%$ reduction $=$ volume of normal neuropil - volume of banded neuropil/volume of normal neuropil.

${ }^{b}$ These lobes received a small supernumerary eye projection appearing in only a few sections which represented only a fraction of this predominantly normal tectum.

'n.a., not applicable.
}

tend to enlarge the measurements. Furthermore, since most measurements are likely to deviate slightly from a line representing the shortest axis of the bands, the actual stripe width will lie below the mode of the measured bandwidth distribution. As can be seen in Figure 7, the modes of all histograms ranged between 90 and $150 \mu \mathrm{m}$ independently of whether the labeled zones arose from supernumerary or normal eye fibers and irrespective of animal age. When compensated for an approximate $45 \%$ shrinkage during histological processing, these data suggest that the width of each band is approximately 150 to $200 \mu \mathrm{m}$ in fresh tissue.

Two additional tendencies should be noted in Figure 7. First, the histograms of postmetamorphic frogs (Fig. 7, $A$ and $B$ ) are consistently broader than those of tadpoles (Fig. 7, $C$ and $D$ ), indicating an increased variability of bandwidth measurements with age. This may reflect subtle distortions in the tectal neuropil produced by late differentiating elements, such as glia or tectal dendritic branches (Currie, 1974; Currie and Cowan, 1974, 1975). Secondly, interbandwidth histograms are broader than bandwidth histograms regardless of which eye was labeled or the age of the animal. We believe this reflects variability in the amount of overlap between terminal zones of the labeled and unlabeled eye.

Electrophysiological demonstration of segregation. Electrode penetrations perpendicular to the surface of doubly innervated tectal lobes recorded relatively normal responses from both the normal and supernumerary eye axon terminals. The radial distribution of on, on-off, and off responses was characteristic of singly innervated tecta and visual field sizes were not significantly different from those of normal frogs (Maturana et al., 1960). Due to the difficulty of distinguishing tectal cell activity within the neuropil from the more prevalent presynaptic activity, we cannot determine at this time whether binocularly driven tectal neurons exist within these dually innervated tecta.
Input segregation was never as pronounced electrophysiologically as it was anatomically (Law and Constantine-Paton, 1980). At most recording sites within the presynaptic neuropil, some activity could be driven by both the supernumerary and the normal eye. Nevertheless, in the dually innervated tecta, eye-specific terminal zones were discernible as a predominance of one eye's responses relative to those elicited through the second retina. Figure $8 B$ illustrates this effect for a position in which the third eye's response was more pronounced than that evoked through the normal superinnervating eye. As an electrode penetrated perpendicular to the tectal surface, the same retina always produced larger and more numerous action potentials at all depths within the neuropil. Shifts in eye dominance were observed only if the recording position was displaced laterally along the tectal surface. In any given preparation, the number of penetrations showing dominance of the normal eye was roughly balanced by a nearly equal number of penetrations in which the third eye predominated.

All 10 of the animals used in eye dominance tests had their third eyes injected with $\left[{ }^{3} \mathrm{H}\right]$ proline and subsequently were processed for anatomical verification of banding. Furthermore, in 2 animals, electrolytic lesions ( 5 to $10 \mu \mathrm{A}$ for $9 \mathrm{sec}$ ) were placed at several sites where either the normal or the supernumerary eye clearly had been most effective in driving activity. Subsequent autoradiography and cresyl violet staining of these brains provided direct correlations between eye dominance and eye-specific bands. Figure $8 A$ shows one of these lesions in a supernumerary eye band where the dominance of the third eye had been electrophysiologically defined.

The preservation of retinotopy. Visuotectal maps were obtained from the doubly innervated tecta of 12 animals. In every case, mapping revealed projections that were ordered internally and aligned relative to the initial embryonic orientation of both retinas. That is, ventral regions of each retina projected to medial tectal loci, dorsal 

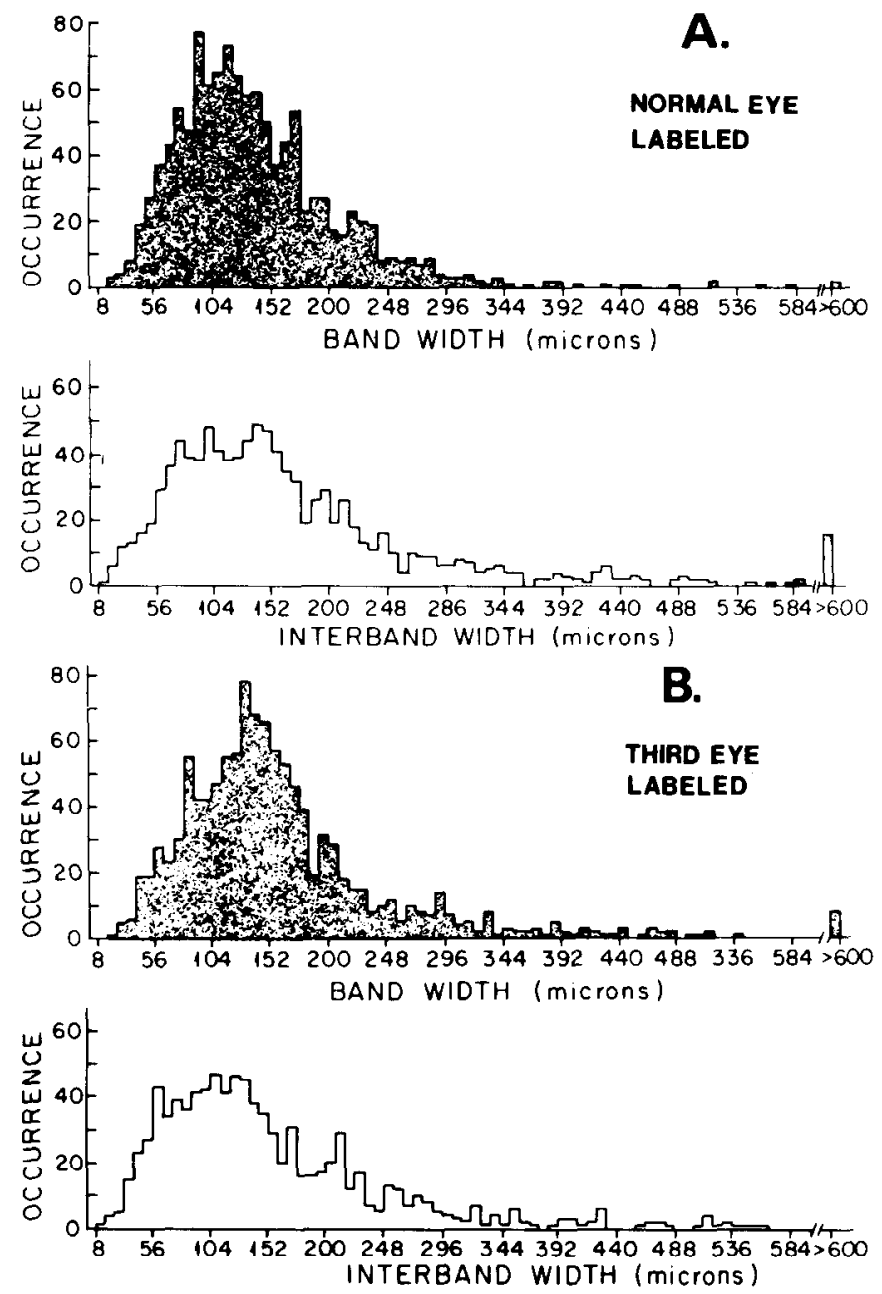
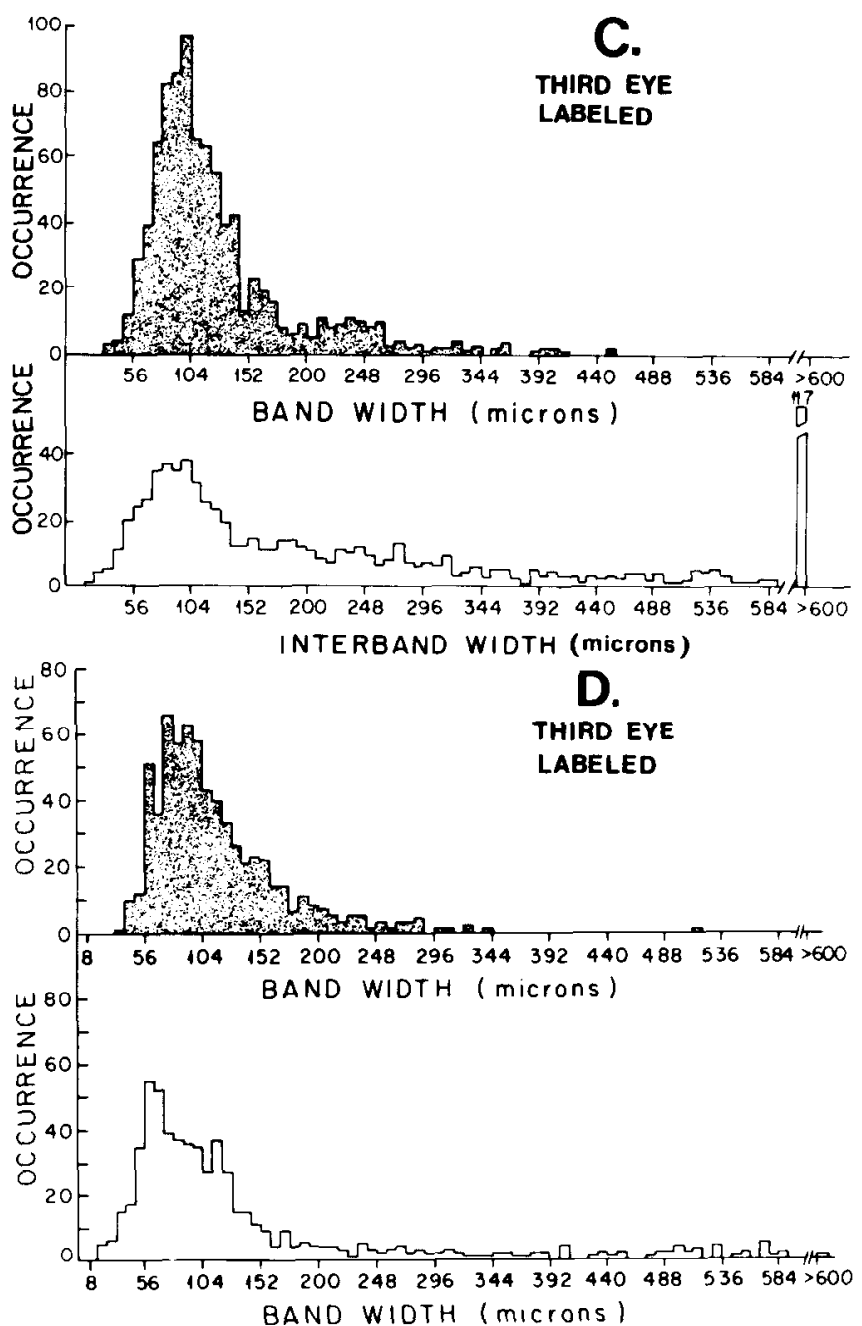

Figure 7. Band- and interbandwidth distributions. Measurements of band and interband lengths from camera lucida tracings of every $10-\mu \mathrm{m}$ section. Bin width is $8 \mu \mathrm{m}$, reflecting the accuracy of our measuring procedure. $A$ and $B$ compare the width distributions of 2 postmetamorphic frogs whose normal eye $(A$, animal 122$)$ versus third eye $(B$, animal 357$)$ had been labeled autoradiographically. In both cases, the most frequent band- and interbandwidths obtained were between 100 and $150 \mu \mathrm{m}$. $C$ and $D$ are histograms from the supernumerary projections of T \& K St. XII tadpole $398(C)$ and T \& K St. XIII tadpole $142(D)$. These histograms peak in the same range as those from the postmetamorphic animals, although the distributions appear to widen with age. Regardless of age, interbandwidths were consistently more variable than the widths of labeled regions. This may reflect differing amounts of overlap of the termination zones from the two eyes. The large number of very wide interband values observed in $C$ is due to the fact that the supernumerary projection split to innervate both lobes in this animal. Width measurements were made for both lobes and combined. Thus, large uninnervated areas are expected here.

retinal regions projected to more lateral tectum, nasal retinal regions were represented in caudal tectum, and temporal retinal regions innervated rostral tectum (Gaze, 1958). These maps were complicated, however, by the abnormal orientation and position of the supernumerary eyes and also by a number of small, localized disruptions of retinal topography.

Figures 9, 10, and 11 contain the visuotectal maps from 3 postmetamorphic frogs in which $\left[{ }^{3} \mathrm{H}\right]$ proline autoradiography subsequently demonstrated eye-specific stripes. The animals depicted vary in the alignment and in the final position of the doubly innervating retinas. The dorsal tectal surface is represented in the lower left corner of each figure, with numbers indicating individual electrode penetration sites. Visual field positions from which activity could be driven are numbered correspondingly in the polar coordinate plots of the visual world. In all of these figures, arrows mark the sequence of numbered sites along the rostrocaudal and lateromedial axes within the tectum and, correspondingly, along the nasaltemporal and inferior-superior axes within the visual world. For example, in the normal eye map of Figure 9, solid arrows connect progressively more caudal sites within the tectum and, within the visual world, a corresponding sequence of visual receptive fields starts at the animal's nose and moves peripherally.

In the preparation shown in Figure 9, all supernumerary eye visual receptive fields fall within the inferior 
A.

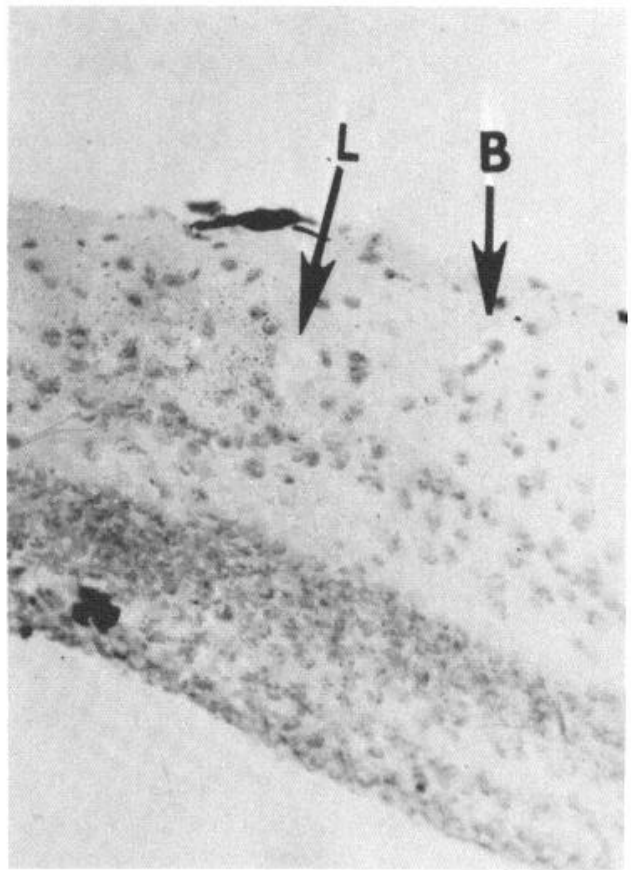

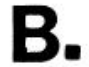

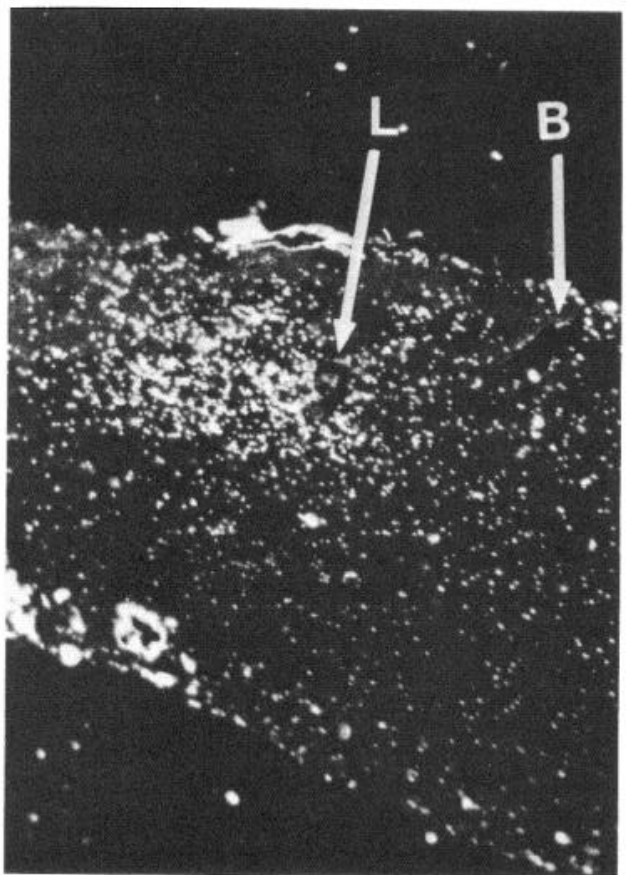

\section{C.}

\section{NORMAL EYE}

off

off

off

\section{THIRD EYE}

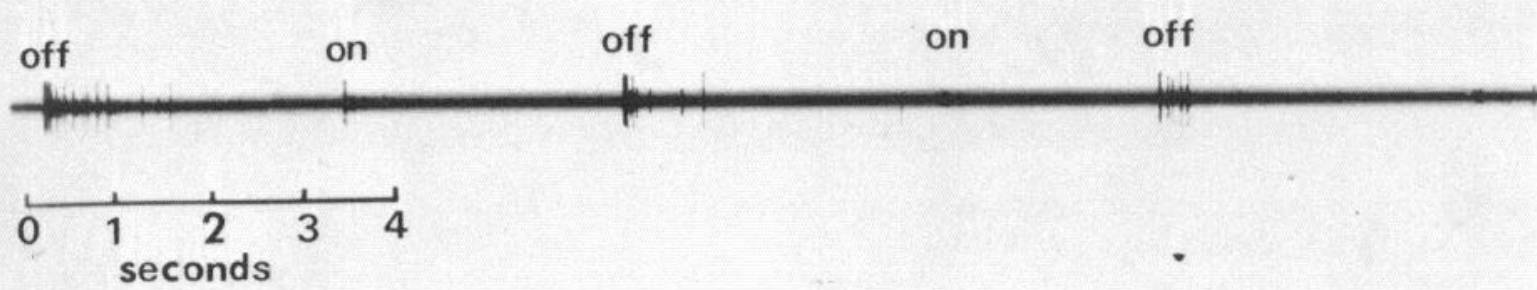

Figure 8. Electrophysiological manifestation of eye-specific termination bands. $A$ and $B$ are light- and dark-field photomicrographs of the same transverse section through the site of a small electrolytic lesion. Eye dominance tests performed prior to lesioning determined the third eye to be dominant at this site. Subsequent autoradiography shows the lesion $(L)$ to be located within an area innervated primarily by axons from the supernumerary eye. ( $B$ marks a blood vessel.) $C$, Grass camera tracings of eye dominance in another animal showing the response from normal eye and third eye fibers at a single tectal site. In this preparation, we used changes in illumination of a $3^{\circ}$ light spot (on, off) located at the center of each eye's receptive field. Only a small, off response was obtained through the normal eye. A much stronger on and off response was elicited through the third eye. In both cases, the first three responses to the light spot are shown. 

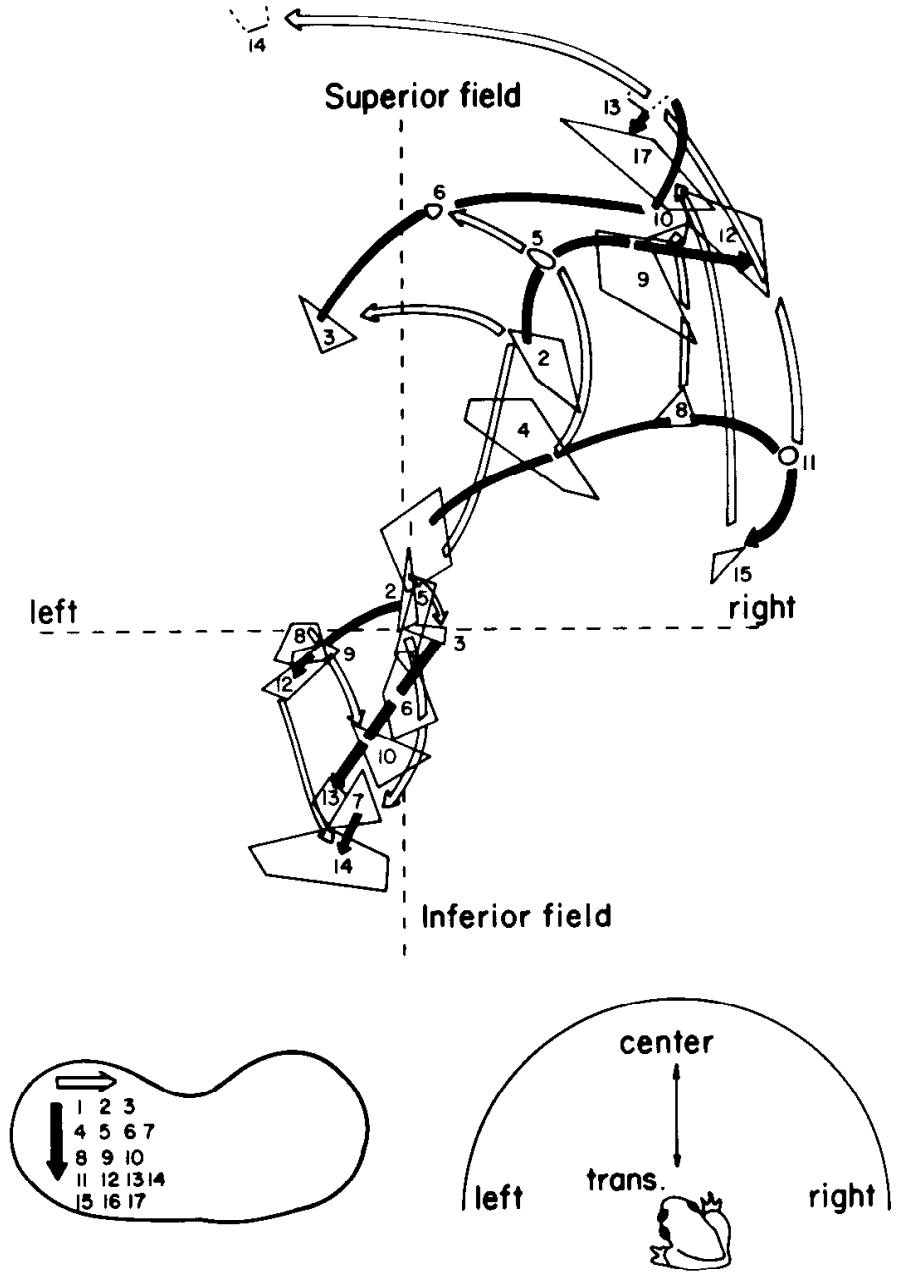

Figure 9. Visuotectal map from a 7-month postmetamorphic three-eyed animal (No. 259). Responses were recorded at each of the 17 numbered tectal recording sites (see dorsal view of tectal lobes in the lower left corner) when a $3^{\circ}$ light spot was turned on or off within the similarly numbered visual fields drawn above on a polar coordinate representation of the perimeter hemisphere. Black corneal occluders assured that only one eye was stimulated at a time. 'The inset on the lower right of the figure illustrates the orientation of the animal's eyes relative to the center of the perimeter hemisphere. Solid arrous in the visual field maps connect points corresponding to successively more caudal tectal positions. Open arrows connect points corresponding to successively more medial tectal positions. Notice that these arrows are roughly orthogonal to each other in both the normal and supernumerary eye map. Visual fields from the normal right eye are contained entirely within the superior visual world, while those of the supernumerary eye (trans) are located in the inferior left visual world. This animal's transplanted eye had been inverted $180^{\circ}$ upon implantation on the left side of the host's head, an orientation that is entirely consistent with the ventral position of the visual fields and the ventral orientation of the open visual field arrows. The orientation of the solid arrows in the transplanted eye's visual field map suggest that this retina was positioned originally on the right side of the donor.

portion of the visual world. Nevertheless, the progression of receptive field positions remains orderly and the solid and open arrows are roughly orthogonal. The map is, in fact, mirror symmetrical and inverted relative to the normal eye's map. Its inverted orientation is consistent with the subsequently determined orientation of the transplanted retina. Inspection of the position of the ventral choroid blood vessel indicated that the graft was rotated $180^{\circ}$ relative to its initial dorsoventral alignment in the donor animal (Sharma and Hollyfield, 1974). The rotation of the map relative to the anterior-posterior axis corresponds to that of a right donor eye. ${ }^{4}$

Figure 10 contains the visuotectal maps obtained for all three eyes of animal 325. These maps illustrate the same constancy in the retinotectal projections independent of the actual orientation of the retinas relative to the visual world. In this preparation, the supernumerary eye was taken from the right side of a donor and implanted on the right side of the host's head. Inspection of the ventral choroid blood vessel revealed that this third retina was rotated approximately $45^{\circ}$ off of its original dorsoventral alignment. The visuotectal map from this eye shows a corresponding $45^{\circ}$ rotation. Its internal order is roughly normal despite local disruptions in the progression of some of the supernumerary eye receptive fields.

The supernumerary "right" eye map in Figure 11 illustrates one of the most extreme cases of internally distorted maps. In this preparation, like those illustrated in Figures 9 and 10, the visuotectal projection from the third eye had roughly orthogonal axes and its overall orientation was consistent with the orientation of the implanted retina. Nevertheless, several supernumerary eye receptive fields are grossly misplaced.

Magnification factor. Calculations of the number of micrometers of anterior tectal surface devoted to each degree of the visual world (magnification factor) were performed for animals 357 and 325 (Figs. 10 and 11) as well as for 2 normal postmetamorphic frogs of the same age and size. Comparative visual receptive field areas first were converted from polar to cartesian coordinates for each of these maps and the centers of each field then were determined using the MOP III. Distances between these centers were measured and the magnification factors were calculated. 'Table III shows that the supernumerary and doubly innervating normal eye's mean magnification factors were not significantly different from the average magnification factor for the noncompeting retina within the same animals. Furthermore, the retinas forced to share a single tectal lobe gave average magnification factors not significantly different from those obtained from completely normal, two-eyed frogs.

\section{Discussion}

Innervation of the frog optic tectum by a normal and supernumerary eye invariably produces a periodic pattern of eye-specific termination zones (Constantine-Pa-

\footnotetext{
${ }^{4}$ The original laterality of this supernumerary eye is uncertain, making a definite statement about the original anterior-posterior retinal axis impossible. However, given that we have nine other cases in which the original anterior-posterior retinal axis is known to map normally onto the tectum, we felt that it was important to present the data for animal 259 in Figure 9 because of its dramatic demonstration that dorsoventral retinal axis inversion results in a corresponding inversion of the supernumerary eye map.
} 


\section{NORMAL EYES}

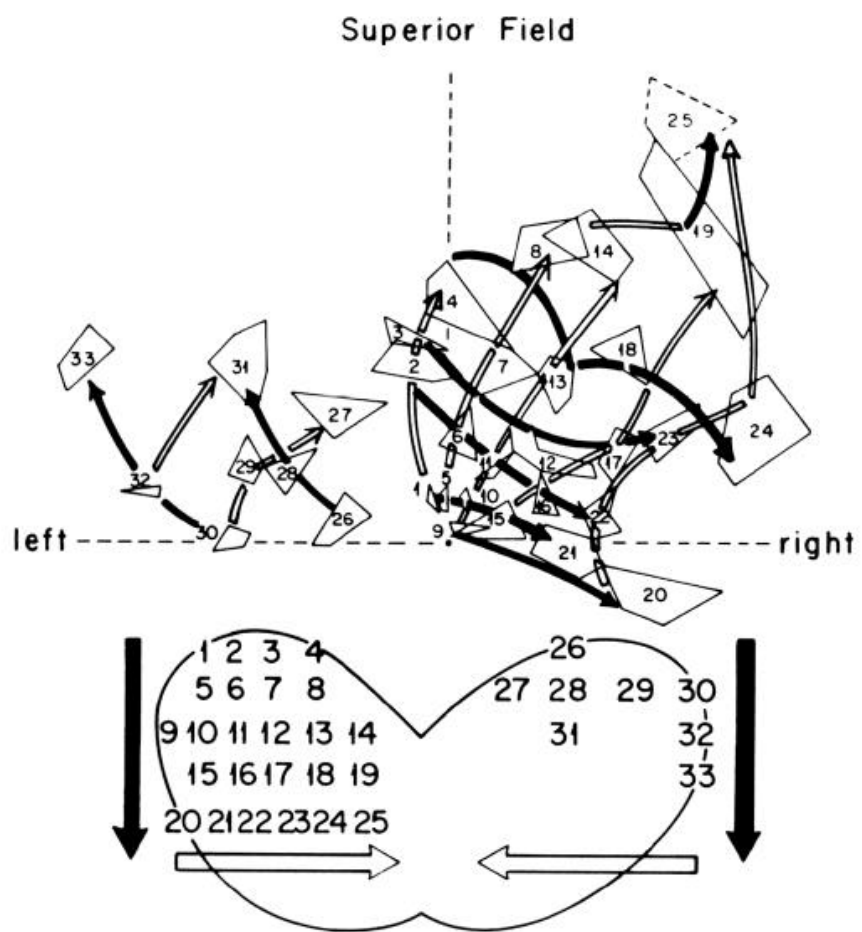

TRANSPLANTED EYE

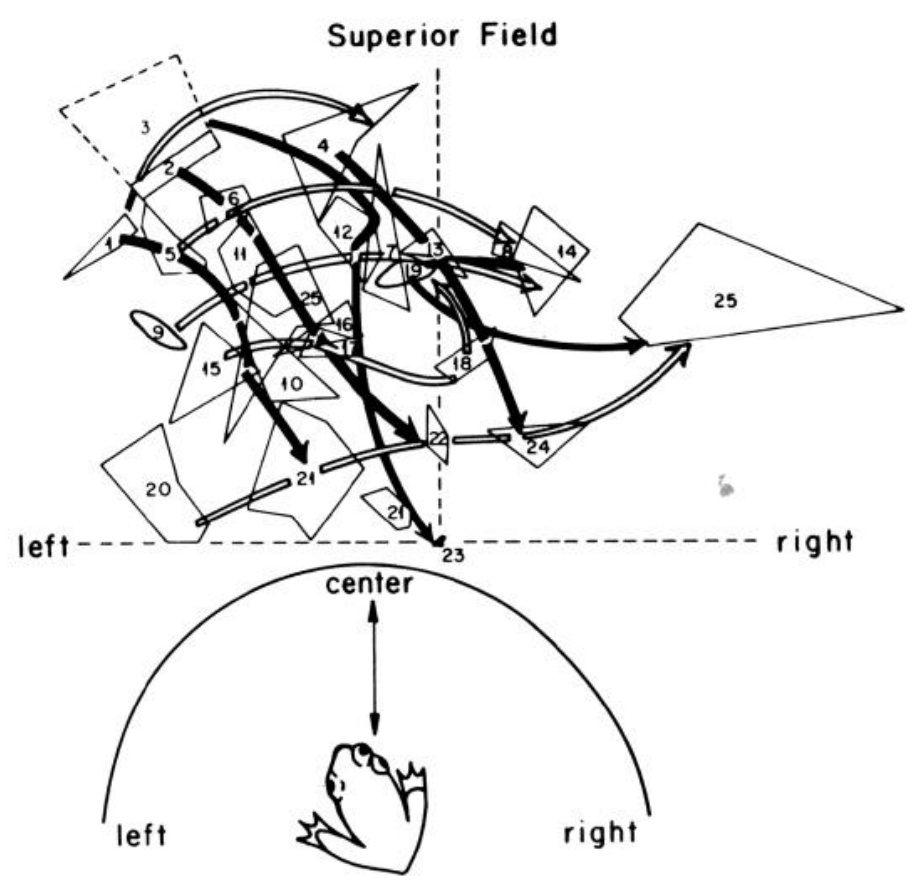

Figure 10. Visuotectal maps from all three eyes of a 1- to 2-month postmetamorphic frog (No. 325) whose supernumerary eye originally had been the donor's right eye. The third eye was located on the right side of this animal's head but was rotated approximately $45^{\circ}$ during implantation. All conventions are the same as in Figure 9 . The visuotectal map of the transplanted eye is shown in the upper right, on a separate set of coordinates, because superimposing it on the normal eye fields rendered the figure unintelligible. As in Figure 9, this supernumerary eye map shows a rotation that is consistent with the approximately $45^{\circ}$ rotation of the initially right transplanted retina. Note a few local distortions in some of the third eye's visual field positions. Fields 8 and 14 appear somewhat displaced and are located nearly in register with field 8 and 14 from the right, co-innervating normal eye.

ton and Law, 1978; Law and Constantine-Paton, 1980). The anatomical analyses in this report extend these initial observations and demonstrate that each eye synapses within mutually exclusive, $150-$ to $200-\mu \mathrm{m}$-wide, elongated slabs of neuropil. The present physiological results indicate that this interdigitating pattern of stripes is superimposed upon two retinotopic maps whose alignment is consistent with the initial embryonic orientation of each eye.

Several different types of interactions between retinal terminals and tectal cells are probably active in these dually innervated tecta and we shall summarize our evidence for each in the sections that follow.

Competition in dually innervated tecta. Competition among afferents for postsynaptic space and among postsynaptic targets for presynaptic inputs often has been implicated in neural development. It is believed to be involved in the terminal sorting processes that occur during the later stages of differentiation in many regions of the nervous system (Prestige and Willshaw, 1975; LeVay and Stryker, 1979; LeVay et al., 1980; Pilar et al., 1980) and it appears to be a critical determinant of both pre- and postsynaptic neuronal survival (for reviews, see Prestige, 1970; Cowan, 1973).

The present morphometric analyses indicate that competition is occurring in the tecta of three-eyed frogs.
Doubly innervated optic lobes showed a moderate hyperplasia $(\sim 30 \%)$ that was restricted largely to the deeper cellular layers. This suggests that the developmental excess of retinal afferents does have an inductive effect in increasing either postsynaptic cell numbers or volumes. However, when only retinotectal neuropil volumes were compared, each competing projection was confined to roughly $50 \%$ of the space occupied by the noncompeting retina of the same animal. Two quite different cellular responses could be involved in this reduction. Increased competition between retinal ganglion cells may have augmented the amount of cell death which normally occurs within the Rana pipiens retina (R. Cigarroa and M. Constantine-Paton, submitted for publication) or the normal number of optic terminals simply may have compressed within the superinnervated tectal lobe. The relationship between compression of a terminal field and cell survival has never been examined carefully in the anuran retinotectal system. Measurements in Xenopus laevis reveal that $70 \%$ of the tectal dendritic surface is normally free of presynaptic terminals (Norden and Freeman, 1979). If the same is true of Rana pipiens, postsynaptic space may be available for hyperinnervation without pronounced presynaptic cell death or major volumetric changes in the dendrites of postsynaptic neurons.

Regardless of the cellular changes accompanying tectal 
NORMAL EYES

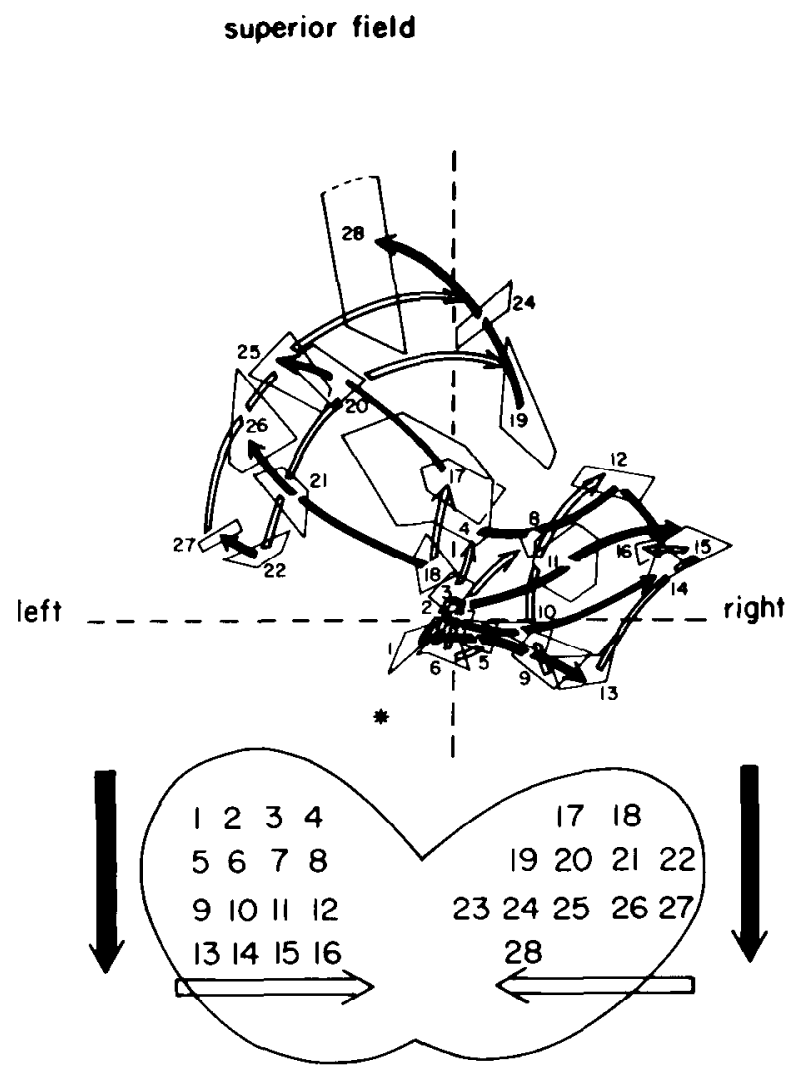

TRANSPLANTED EYES

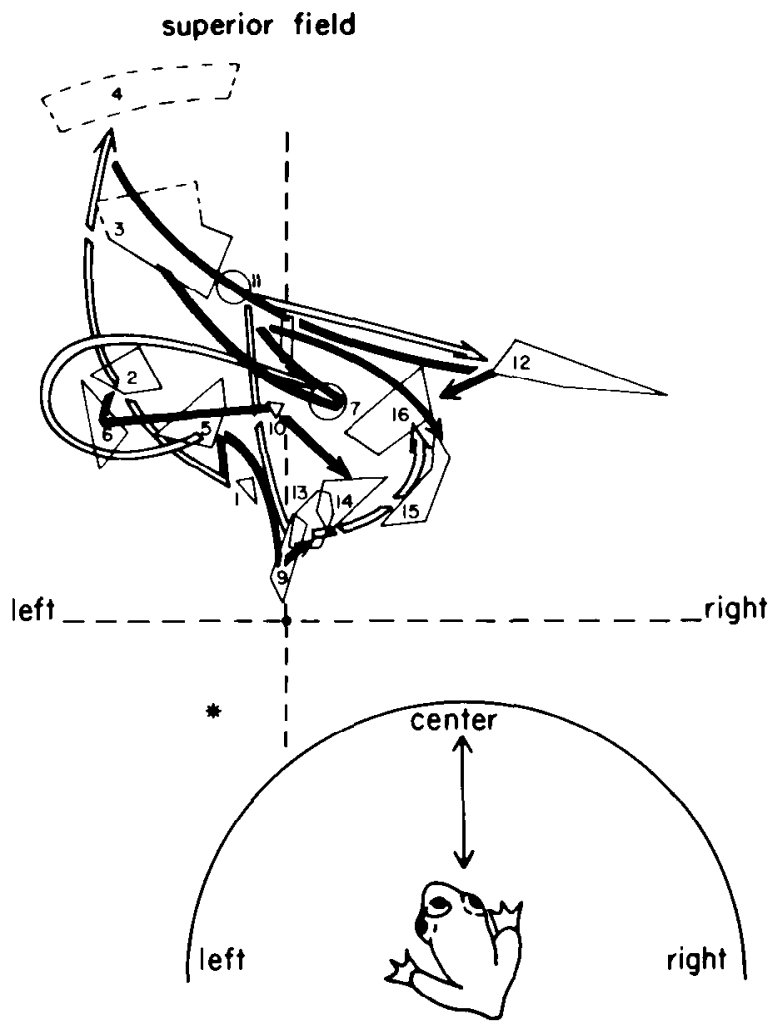

Figure 11. Visuotectal maps from the three eyes of a 4-month postmetamorphic three-eyed frog (No. 357). All conventions are the same as in Figure 10 except that the animal was tilted approximately $30^{\circ}$ below the horizontal axis of the perimeter's hemisphere. Thus, the asterisk in each of the visuotectal maps indicates the location of the animal's nose and, thereby, its anterior-posterior alignment. The third eye of this frog had originally been the donor's right eye. It was implanted on the left side of the host's head pointing upward. The maps from both normal eyes appeared to be quite orderly, although rotated somewhat clockwise due to the animal's centering position within the perimeter. Some order can be discerned also in the transplanted eye map. This is, however, one of the most distorted supernumerary eye maps obtained. Although the general direction of the arrows is correct for the position and original laterality of the third eye, many distortions are evident. A few misplaced fields also can be seen in the map from the superinnervating right eye of the host (see, for example, field 16).

\section{TABLE III}

Magnification factor (micrometers of tectal surface/degree of visual world) in normal and superinnervating retinal projections

The number of micrometers of tectal surface over which $1^{\circ}$ of visual world was represented (MF) was determined for analogous anterior regions of tecta. MF values are similar in the noncompeting eye's projections and in the projections from the two superinnervating retinas. Furthermore, the MF values obtained within the doubly innervated tecta were not significantly different from values obtained in normal animals.

\begin{tabular}{lc}
\hline \multicolumn{1}{c}{ Projections } & MF \\
Three-eyed animal 325 & \\
Noncompeting left eye & $8.2 \pm 5.7$ \\
Competing right eye & $7.9 \pm 5.4$ \\
Supernumerary eye & $6.0 \pm 3.5$ \\
& \\
Three-eyed animal 357 & \\
Noncompeting left eye & $8.9 \pm 3.5$ \\
Competing right eye & $8.4 \pm 4.4$ \\
Supernumerary eye & $9.5 \pm 8.2$ \\
& \\
Normal animals & \\
1 & $8.6 \pm 3.8$ \\
11 & $9.6 \pm 5.4$ \\
\hline
\end{tabular}

innervation in three-eyed frogs, reductions in the volumes of superinnervating projections should be reflected in measurements of magnification factor (micrometers per degree) because the entire visual field must be represented in a smaller tectal area. The ability to detect changes in the magnification factor depends critically, however, on the precision of the physiological recording techniques. It is essential that each eye be centered along its axis so that identical parts of each retina can be compared systematically. Moreover, in order to assess the magnification factor, closely spaced electrode penetrations would have to be made. It is not surprising, therefore, that our calculations from visuotectal mapping data failed to show any change, but the result is not definitive without such specifically designed experiments. Lesions and subsequent reconstruction of the tectal surface following the recording session would have to be performed in order to know if successive electrode penetration sites were along, within, or across the bands. If compression occurs only along the axis which is perpendicular to eye-spccific stripes, then magnification factor calculations will be influenced by the orientation of the electrode penetration series relative to the orientation of 
the bands. Subsequent experiments should resolve these ambiguities.

Parameters that might cause banding. The input segregation pattern produced within three-eyed Rana pipiens is remarkably stereotyped. In young, binocular frogs, an identical pattern of stripes can be induced between right and left eye terminals following the ablation of one tectal lobe ( $\mathrm{I}$ aw and Constantine-Paton, 1980). Similar eye-specific bands or patches have been reported when two retinas are forced to share one tectum in goldfish, salamanders, and other anurans (Levine and Jacobson, 1975; Meyer, 1979a; Straznicky et al., 1980; W. Harris, personal communication). The consistent production of such segregation suggests that the cellular forces inducing them are a normal part of retinotectal synapse formation.

The current results indicate that the neuronal interactions which sort axons into eye-specific bands are not affected by eye laterality, the length of each optic tract, or the orientation of the eye on the host animal's head. It also appears unlikely that these segregated synaptic zones reflect bundling of axons within the optic tracts since no evidence of such patterned segregation was observed in the tracts of three-eyed frogs when both eyes were labeled differentially and the brains were sectioned and examined in transverse, sagittal, and horizontal planes.

Instead, we suggest that the production of eye-specific banding can be explained as a necessary correlate of two forces that normally occur during synaptogenesis within the tectal neuropil. These forces are: (1) graded affinities between particular retinal and tectal regions and (2) interactions between the afferents which preserve retinal neighborhood relationships during termination. According to this model, the consistent alignment of the retinotectal map is produced by the spatial arrangement of molecules that mediate graded affinities between optic fibers and tectal cells. Point to point order of the projection within each general tectal area is created subsequently by local interactions between optic fibers. The rule is to stabilize synapses from axons whose somata are physical neighbors within the retina at the expense of synapses from nonadjacent cells.

LeVay et al. (1975) have suggested that the ocular dominance columns of cat and primate visual cortex could arise as a result of conflict between two topographic mapping mechanisms that are essentially identical to those outlined above. We think that experimentally produced striped tecta constitute strong support for their proposal. Our reasoning is as follows. If fiber-fiber sorting (without retinotectal matching) was responsible for development of the visual map, then, when two retinas innervate one tectum, they should divide the neuropil into only two eye-specific regions. Each zone would be the exclusive, retinotopically organized territory of one eye. On the other hand, if only retinal to tectal matching occurred (without fiber-fiber sorting), each retina should terminate without reference to the other retina and in a continuous manner. Consequently, the two projections should overlap. However, if both forces occur simultaneously, retinotectal matching will act to align the projection and spread both sets of optic fibers over the entire tectal surface, while fiber-fiber sorting will dictate that axons from each retina terminate together. Thus, in doubly innervated tectal lobes, the interdigitating eyespecific bands represent a compromise. Cells from each ganglion cell population compete equally to maximize their contacts in particular tectal regions and preserve retinotopy. The banding allows them simultaneously to minimize the frequency of contacts with the "non-neighboring" optic terminals of the other eye. Such a model is attractive because it requires little pre-programed information. Retinal and tectal positional cues could be quite general, perhaps in the form of shallow gradients merely serving to assure that correct retinal and tectal quadrants are in contact.

Mapping models in the retinotectal system. Considerable debate in the retinotectal literature concerns the nature or presence of tectal positional markers. Although recent experiments support the independent existence of positional or polarity information within the optic tectum (Straznicky et al., 1979; Constantine-Paton and FerrariEastman, 1979, 1981; O'Leary and Cowan, 1980), little biochemical evidence for such markers is available (Barbera, 1975; see Gottlieb and Glaser, 1980 for review). Consequently, some recent models have suggested that retinotopic order is based solely on interactions between optic fibers (Chung and Cooke, 1978; Horder and Martin, 1978). These are obviously demonstrable in experiments where projections expand (Schmidt, 1978), compress (Sharma, 1972; Yoon, 1972; Udin, 1977), or form inter nally ordered maps without apparent reference to the particular tectal tissue which they innervate (Jacobson and Levine, 1975; Chung and Cooke, 1978; Bunt et al., 1979; Meyer, 1980b).

Models based only on fiber-fiber sorting also have been fostered by studies that reveal a high degree of retinotopy within the optic nerve and tract (Bunt and Horder, 1978; Levinthal and Bodick, 1979; Scholes, 1979; Rusoff and Easter, 1980). Thus, some investigators suggest that fasciculation of retinal fibers could maintain relative order during growth and then reproduce it within the target structure (Cooke and Horder, 1977; Chung and Cooke, 1978; Horder and Martin, 1978; Bodick and Levinthal, 1980; Rager and von Oeynhausen, 1979).

The present results are not consistent with ideas that place all mapping information within the afferent fiber projections. It would be necessary to postulate sorting into stereotyped eye-specific fascicles within the optic tract of three-eyed frogs in order to produce retinotopic order and bands within one tectum simultaneously. We have no evidence for such ordering. Overlap of the two superinnervating projections was always observed in the medial and lateral optic tracts and the fasciculation that was observed occasionally in the diencephalon never corresponded to tectal bands.

Irrespective of the organizing role played by the tectum, the majority of mapping models, as well as our present results, require some mechanism whereby axons from physically neighboring retinal ganglion cells recognize one another during termination. von der Malsburg and Willshaw (1977) have suggested that local interactions which could result in retinotopy might be based on a limited number of chemical markers distributed ran- 
domly within the eye and transported down retinal ganglion cell axons. Using these markers, axonal interactions mediated through tectal cells could stabilize synapses carrying similar labels (Willshaw and von der Malsburg, 1979). This system would maintain the neighborhood relationship of the retinal axons and also can produce bands (von der Malsburg, 1979).

It may not be necessary, however, to postulate chemical retinal markers in order to produce retinal localespecific recognition. Synchronized patterns of electrical activity could substitute for different chemical moieties and identify neighboring retinal ganglion cells (von der Malsburg and Willshaw, 1976; Willshaw and von der Malsburg, 1976).

Synaptic stabilization as a result of synchronized activity patterns has many precedents in the literature (Hebb, 1949; Marr, 1969; von der Malsburg, 1973; Stent, 1973; Changeux and Danchin, 1976). Within the visual system, considerable experimental evidence indicates that synchrony of activity can affect the final termination pattern of striate cortical neurons (for examples, see Hubel and Wiesel, 1965; Stryker et al., 1978; Singer et al., 1979), and in Xenopus laevis, similarity in activity between direct and indirect optic projections appears to be responsible for the binocularity of tectal cells (Keating and Gaze, 1970; Keating, 1975). It is also possible that the local distortions observed in some of the visuotectal maps of three-eyed frogs (Fig. 10) could reflect the same type of activity-dependent terminal stabilization.

Conclusions. Evidence from our three-eyed frog preparations strongly supports the involvement of two competitive synaptogenetic forces in the formation of eyespecific stripes. Pre- and postsynaptic position-dependent interactions would be capable of spreading and aligning both projections, while fiber-fiber interactions based on retinal neighborhood relations could create internal order and cause segregation into bands. We think that these same two mechanisms are responsible for the alignment and the fine point-to-point precision of the continuous retinal projection in unmanipulated frogs. In fact, other investigators in the retinotectal system recently have advanced a similar two-component model to explain observations on singly innervated tectal lobes (for example, see Fraser, 1980).

The more general significance of our results, however, lies in the striking similarity between banded frog tecta and the afferent segregation patterns present in the normal mammalian central nervous system. In many instances, it is known that the segregated afferents of the mammalian brain also are mapped stereotypically within the postsynaptic structure. Our interpretation of frog tectal stripes implies that the production of these similar, normally occurring patterns need not involve mechanisms that are devoted exclusively to source-specific segregation. Instead, we suggest that, whenever distinct presynaptic populations are similarly specified for a single postsynaptic surface, highly elaborate input patterns may occur which are related mechanistically to the formation of topographic maps.

\section{References}

Adams, J. C. (1977) Technical consideration in the use of horseradish peroxidase as a neuronal marker. Neuroscience
2: $141-145$.

Barbera, A. J. (1975) Adhesive recognition between developing retinal cells and the optic tecta of the chick embryo. Dev. Biol. 46: 167-191.

Bodick, N., and C. Levinthal (1980) Growing optic nerve fibers follow neighbors during embryogenesis. Proc. Natl. Acad. Sci. U. S. A. 77: 4374-4378.

Bunt, S. M., and T. J. Horder (1978) Evidence for an orderly arrangement of optic axons in the central pathways of vertebrates and its implication for the formation and regeneration of optic projections. Soc. Neurosci Abstr. 4: 468.

Bunt, S. M., T. J. Horder, and K. A. C. Martin (1979) The nature of nerve fibre guidance mechanisms responsible for the formation of an orderly central visual projection. In Developmental Neurobiology of Vision, K. Freeman, ed., pp. 331-343, Plenum, New York.

Casagrande, V. A., and L. C. Skeen (1980) Organization of ocular dominance columns in Galago demonstrated by autoradiographic and deoxyglucose methods. Soc. Neurosci. Abstr. 6: 315 .

Changeux, J. -P., and A. Danchin (1976) Selective stabilization of developing synapses, as a mechanism for the specification of neuronal networks. Nature 264: 705-712.

Chung, S. H., and J. Cooke (1978) Observations on the formation of the brain and of nerve connections following embryonic manipulation of the amphibian neural tube. Proc. R. Soc. Lond. (Biol.) 201: 335-373.

Colman, D. R., F. Scalia, and E. Cabrales (1976) Light and electron microscopic observations on the anterograde transport of HRP in the optic pathway of the mouse and rat. Brain Res. 102: 156-163.

Cooke, J. E., and T. J. Horder (1977) The multiple factors determining retinotopic order in the growth of optic fibers into the optic tectum. Philos. Trans. R. Soc. Lond. (Biol.) 278: 261-276.

Constantine-Paton, M. (1978) Central projections of anuran optic nerves penetrating hindbrain or spinal cord regions of the neural tube. Brain Res. 158: 31-43.

Constantine-Paton, M., and R. R. Capranica (1976) Axonal guidance of developing optic nerves in the frog. I. Anatomy of the projection from transplanted eye primordia. J. Comp. Neurol. 170: 17-32.

Constantine-Paton, M. and P. Ferrari-Eastman (1979) Tectal connectivity in the frog following embryonic removal of eye primordia. Soc. Neurosci. Abstr. 5: 156.

Constantine-Paton, M., and P. Ferrari-Eastman (1981) Topographic and morphometric effects of bilateral embryonic eye removal on the optic tectum and nucleus isthmus of the leopard frog. J. Comp. Neurol. 196: 645-666.

Constantine-Paton, M., and M. I. Law (1978) Eye-specific termination bands in tecta of three-eyed frogs. Science 202: 639641.

Courville, J. (1975) Distribution of olivocerebellar fibers demonstrated by a radioautographic tracing method. Brain Res. 95: 253-263.

Cowan, W. M. (1973) Neuronal death as a regulative mechanism in the control of cell number in the nervous system. In Development and Aging in the Nervous System, M. Rockstein, ed., pp. 19-41, Academic Press, New York.

Currie, J. (1974) Some observations on the development of the visual system of the frog. Chapter II. Thesis, Washington University, St. Louis.

Currie, J., and W. M. Cowan (1974) Some observations on the early development of the optic tectum in the frog Rana pipiens with special reference to the effects of early eye removal on mitotic activity in the larval tectum. J. Comp. Neurol. 156: 123-142.

Currie, J., and W. M. Cowan (1975) The development of the retino-tectal projections in Rana pipiens. Dev. Biol. 46: 103- 
119.

Fitzpatrick, K. A., and T. J. Imig (1980) Auditory corticocortical connections in the owl monkey. J. Comp. Neurol. 192: 589-610.

Fraser, S. E. (1980) A differential adhesion approach to the palterning of nerve connections. Dev. Biol. 79: 453-464.

Gaze, R. M. (1958) The representation of the retina on the optic lobe of the frog. Q. J. Exp. Physiol. 43: 209-214.

Gaze, R. M., and P. Grant (1978) The diencephalic course of regenerating retinotectal fibers in Xenopus tadpoles. J. Embryol. Exp. Morphol. 44: 201-216.

Gilbert, C. D., and T. N. Wiesel (1980) Interleaving projection bands in cortico-cortical connections. Soc. Neurosci. Abstr. 6: 315 .

Goldman, P. S., and W. J. Nauta (1977a) Columnar distribution of cortico-cortical fibers in the frontal association, limbic and motor cortex of the developing rhesus monkey. Brain Res. 122: 393-413.

Goldman, P. S., and W. J. Nauta (1977b) An intricately patterned prefrontocaudate projection in the rhesus monkey. J. Comp. Neurol. 171: 369-386.

Gottlieb, D. I., and L. Glaser (1980) Cellular recognition during neural development. Annu. Rev. Neurosci. 3: 303-318.

Graybiel, A. M. (1975) Anatomical organization of retinotectal afferents in the cat. An autoradiographic study. Brain Res. 96: 1-23.

Graybiel, A. M. (1976) Evidence for banding of the cat's ipsilateral retinotectal connection. Brain Res. 114: 318-327.

Graybiel, A. M. (1978) Organization of the nigrotectal connection: An experimental tracer study in the cat. Brain Res, 143: 339-348.

Graybiel, A. M., and C. W. Ragsdale (1980) Clumping of acetylcholinesterase in the developing striatum of the human fetus and young infant. Proc. Natl. Acad. Sci. U. S. A. 77: 1214-1218.

Groenewegen, H. J., and J. Voogd (1977) The parasagittal zonation within the olivocerebellar projection. 1. Climbing fiber distribution in the vermis of cat cerebellums. J. Comp. Neurol. 174: 417-488.

Groenewegen, J. J., J. Voogd, and S. L. Freeman (1979) The parasagittal zonation within the olivocerebellar projection. II. Climbing fiber distribution in the intermediate and hemispheric parts of the cat cerebellum. J. Comp. Neurol. 183: $551-602$.

Hebb, D. O. (1949) Organization of Behavior, John Wiley and Sons, New York.

Horder, T. J., and K. A. C. Martin (1978) Morphogenetics as an alternative to chemospecificity in the formation of nerve connections. In Cell-Cell Recognition, Society for Experimental Biology Symposium, A. S. G. Curtis, ed., pp. 275-358, Cambridge University Press, New York.

Hubel, D. H., and T. N. Wiesel (1965) Binocular interaction in striate cortex of kittens reared with artificial squint. J. Neurophysiol. 28: 1041-1059.

Hubel, D. H., and T. N. Wiesel (1969) Anatomical demonstration of columns in the monkey striate cortex. Nature 221: $747-750$.

Hubel, I. H., S. LeVay, and T. N. Wiesel (1975) Mode of termination of retinotectal fibers in macaque monkeys: An autoradiographic study. Brain Res. 96: 25-40.

Imig, T. J., and J. F. Brugge (1978) Sources and terminations of callosal axons related to binaural and frequency maps in primary auditory cortex of the cat. J. Comp. Neurol. 182: 637-660.

Jacobson, M., and R. L. Levine (1975) Plasticity in the adult frog brain: Filling the visual scotoma after excision or translocation of parts of the optic tectum. Brain Res. 88: 339-345. Jones, E. G., H. Burton, and R. Porter (1975) Commissural and cortico-cortical "columns" in the somatic sensory cortex of primates. Science 190: 572-574.

Jones, E. G., J. D. Coulter, and S. H. C. Hendry (1978) Intracortical connectivity of architectonic fields in the somatic sensory, motor and parietal cortex of monkeys. J. Comp. Neurol. 181: 291-348.

Keating, M. J. (1975) The time-course of experience-dependent synaptic switching of visual connections in Xenopus laevis. Proc. R. Soc. Lond. (Biol.) 189: 603-610.

Keating, M. J., and R. M. Gaze (1970) Rigidity and plasticity in the amphibian visual system. Brain Behav. Evol. 3: 102-120.

Killackey, H. P. (1973) Anatomical evidence for cortical subdivisions based on vertically discrete thalamic projections from the ventral posterior nucleus to cortical barrels in the rat. Brain Res. 51: 326-331.

Künzle, H. (1976) Alternating afferent zones of high and low axon terminal density within the Macaque motor cortex. Brain Res. 106: 365-370.

Law, M. I., and M. Constantine-Paton (1980) Right and left eye bands in frogs with unilateral tectal ablations. Proc. Natl. Acad. Sci. U. S. A. 77: 2314-2318.

Lázár, G. (1980) Organization of the frog visual systcm. In Recent Developments of Neurobiology in Hungary, K. Lissák, ed., Vol. III, pp. 9-50, Akademiai Kiado, Budapest.

LeVay, S., and M. P. Stryker (1979) The development of ocular dominance columns in the cat. Soc. Neurosci. Symp. 4: 8398.

LeVay, S., D. H. Hubel, and T. N. Wiesel (1975) The pattern of ocular dominance columns in macaque visual cortex revealed by a reduced silver stain. J. Comp. Neurol. 159: 559-576.

LeVay, S., T. N. Wiesel, and D. H. Hubel (1980) The development of ocular dominance columns in normal and visually deprived monkeys. J. Comp. Neurol. 191: 1-51.

Levine, R., and M. Jacobson (1975) Discontinuous mapping of retina onto tectum innervated by both eyes. Brain Res. 98 : 172-176.

Levinthal, C., and N. Bodick (1979) Self-assembly of a nerve: Optic fibers follow their neighbors in embryogenesis. In Cell Lineage, Stem Cells and Cell Determination, N. Le Douarin, ed., pp. 347-352, Elsevier/North-Holland Biomedical Press, Amsterdam.

Marr, D. (1969) A theory of cerebellar cortex. J. Physiol. (Lond.) 202: $437-470$.

Maturana, H. R., J. Y. Lettvin, W. S. McCulloch, and W. H. Pitts (1960) Anatomy and physiology of vision in the frog (Rana pipiens). J. Gen. Physiol. Suppl. 43: 129-175.

Meyer, R. (1979a) Extra optic fibers exclude normal fibers from tectal regions in goldfish. J. Comp. Neurol. 183: 883-902.

Meyer, R. (1979b) Retinotectal projections in goldfish to an inappropriate region with a reversal in polarity. Science 205 : 819-821.

Newsome, W. T., and J. M. Allman (1980) Interhemispheric connections of visual cortex in the owl monkey, Aotus trivirgatus, and the Bushbaby, Galogo senegalensis. J. Comp. Neurol. 194: 209-233.

Norden, J. J., and J. A. Freeman (1979) A quantitative morphometric analysis of transneuronal changes following longterm denervation of the optic tectum in Xenopus. Soc. Neurosci. Abstr. 5: 801.

O'Leary, D. D. M., and W. M. Cowan (1980) Observations on the effects of monocular and binocular eye removal on the development of the chick's visual system. Soc. Neurosci. Abstr. 6: 297.

Oscarsson, O. (1973) Functional organization of spinocerebellar paths. In Handbook of Sensory Physiology. Vol. 2: Somatosensory System, A. Iggo, ed., pp. 339-380, Springer-Verlag, Berlin. 
Pilar, G., L. Landmesser, and L. Burstein (1980) Competition for survival among developing ciliary ganglion cells. J. Neurophysiol. 43: 233-254.

Pollack, J. G., and J. C. Hickey (1979) The distribution of retino-collicular terminals in rhesus monkeys. J. Comp. Neurol. 185: 587-602.

Prestige, M. C. (1970) Differentiation, degeneration and the role of the periphery: Quantitative considerations. In The Neurosciences: Second Study Program, F. O. Schmitt, ed., pp. 73-83, Rockefeller University Press, New York.

Prestige, M. C., and D. J. Willshaw (1975) On a role for competition in the formation of patterned neural connections. Proc. R. Soc. Lond. (Biol.) 190: 77-98.

Rager, G., and B. von Oeynhausen (1979) Ingrowth and ramification of retinal fibers in the developing optic tectum of the chick. Exp. Brain. Res. 35: 213-227.

Rakic, P. (1977) Prenatal development of the visual system in rhesus monkey. Philos. Trans. R. Soc. (Biol.) 278: 245-260.

Rugh, R. (1962) Experimental Embryology Techniques and Procedures, Ed. 3, Burgess Publishing Co., Minneapolis.

Rusoff, A. C., and S. S. Easter (1980) Order in the optic nerve of goldfish. Science 208: 311-312.

Scalia, F., and D. K. Colman (1974) Aspects of the central projection of the optic nerve in the frog as revealed by the anterograde migration of horseradish peroxidase. Brain Res. 79: 496-504.

Scalia, F., H. Knapp, M. Halpern, and W. Riss (1968) New observations on the retinal projection in the frog. Brain Behav. Evol. 1: 324-353.

Schmidt, J. T. (1978) Retinal fibers alter tectal positional markers during the expansion of the half retinal projection in goldfish. J. Comp. Neurol. 177: 279-300.

Scholes, J. H. (1979) Nerve fibre topography in the retinal projection to the tectum. Nature 278: 620-624.

Shanks, M. F., A. J. Rockel, and T. P. S. Powell (1975) The commissural fibre connections of the primary somatic sensory cortex. Brain Res. 98: 166-171.

Sharma, S. C. (1972) Reformation of the retinotectal projections after various tectal ablations in adult goldfish. Exp. Neurol. 34: 171-182.

Sharma, S. C., and J. G. Hollyfield (1974) Specification of retinal central connections in Rana pipiens before the appearance of the first post-mitotic ganglion cell. J. Comp. Neurol. 155: 395-408.

Shatz, C. J., S. H. Lindstrom, and T. N. Wiesel (1977) The distribution of afferents representing right and left eyes in the cat's visual cortex. Brain Res. 131: 103-116.

Shumway, W. (1940) Stages in the normal development of Rana pipiens. I. External forms. Anat. Rec. 83: 309-315.

Singer, W., F. Tretter, and V. Yinon (1979) Inverted monocular vision prevents ocular dominance shift in kittens and impairs the functional state of visual cortex in adult cats. Brain Res. 164: 294-299.

Stent, G. S. (1973) A physiological mechanism for Hebb's postulate of learning. Proc. Natl. Acad. Sci. U. S. A. 70: 997-
1001.

Straznicky, C., R. M. Gaze, and M. J. Keating (1979) Selective optic fibre projection from compound eyes to the tectum during development in Xenopus. Soc. Neurosci. Abstr. 5: 181.

Straznicky, D., D. Tay, and J. Hiscock (1980) Segregation of optic fibre projections into eye-specific bands in dually innervated tecta in Xenopus. Neurosci. Lett. 19: 131-136.

Stryker, M. P., H. Sherk, A. G. Leventhal, and H. V. B. Hirsch (1978) Physiological consequences for the cat's visual cortex of effectively restricting early visual experience with oriented contours. J. Neurophysiol. 41: 896-909.

Székely, G., and G. Lázár (1976) Cellular and synaptic architecture of the optic tectum. In Frog Neurobiology, R. Llinás and W. Precht, eds., pp. 407-434, Springer-Verlag, Berlin.

Taylor, A. C., and J. J. Kollros (1946) Stages in the normal development of Rana pipiens larvae. Anat. Rec. 94: 7-28.

Udin, S. (1977) Rearrangements of the retinotectal projection in Rana pipiens after unilateral caudal half-tectum ablation. J. Comp. Neurol. 173: 561-582.

von der Malsburg, C. (1973) Self-organization of orientation sensitive cells in the striate cortex. Kybernetik 14: 85-100.

von der Malsburg, C. (1979) Development of ocularity domains and growth behavior of axon terminals. Biol. Cybern. 32: 4962.

von der Malsburg, C., and D. J. Willshaw (1976) Mechanism for producing continuous neural mappings: Ocularity dominance stripes and ordered retinotectal projections. Exp. Brain Res. Suppl. I: 463-469.

von der Malsburg, C., and D. J. Willshaw (1977) How to label nerve cells so that they can interconnect in an ordered fashion. Proc. Natl. Acad. Sci. U. S. A. 74: 5176-5178.

Wiesel, T. N., D. H. Hubel, and D. M. K. Lam (1974) Autoradiographic demonstration of ocular dominance columns in the monkey striate cortex by means of transneuronal transport. Brain Res. 79: 273-279.

Willshaw, D. J., and C. von der Malsburg (1976) How patterned neural connections can be set up by self-organization. Proc. R. Soc. Lond. (Biol.) 194: 431-445.

Willshaw, D. J., and C. von der Malsburg (1979) A marker induction mechanism for the establishment of ordered neural mappings; its application to the retinotectal problem. Philos. Trans. R. Soc. Lond. (Biol.) 287: 203-243.

Wise, S. P., and E. G. Jones (1976) The organization and postnatal development of the commissural system of the somatic sensory cortex in the rat. J. Comp. Neurol. 168: 313343.

Wise, S. P., and E. G. Jones (1977) Cells of origin and terminal distribution of descending projections of the rat somatic sensory cortex. J. Comp. Neurol. 175: 129-158.

Woolsey, T. A., and H. Van der Loos (1970) The structural organization of layer IV in the somatosensory region (SI) of the mouse cerebral cortex. Brain Res. 17: 205-242.

Yoon, M. G. (1972) Reversibility of the reorganization of retinotectal projection in goldfish. Exp. Neurol. 35: 565-577. 